\title{
PARTIDOS POLÍTICOS, OPINIONES POLÍTICAS E INTERNET: LA LESIÓN DEL DERECHO A LA PROTECCIÓN DE DATOS PERSONALES ${ }^{1}$
}

\author{
MÓNICA ARENAS RAMIRO \\ Profesora Contratada Doctora de Derecho Constitucional \\ Universidad de Alcalá
}

\begin{abstract}
SUMARIO
I. Introducción. II. Transformación digital, partidos políticos, datos personales y elecciones. III. Antecedentes de una inconstitucionalidad anunciada. IV. La STC 76/2019: la lesión del contenido esencial del derecho a la protección de datos personales. V. El siguiente paso: principios y garantías adecuadas. VI. A modo de reflexión final
\end{abstract}

\section{INTRODUCCIÓN}

La transformación digital que vive nuestra sociedad tiene un impacto directo en nuestras vidas y en nuestros derechos. Esta digitalización ha llegado también a los procesos democráticos y no sólo a la forma en la que los ciudadanos participan y se hacen oir por sus representantes y gobernantes, sino que ha modificado la forma en la que los candidatos que van a concurrir a los citados procesos electorales, llegan a los ciudadanos, les informan y captan sus votos. ${ }^{2}$

1 El presente artículo se publica en el marco del acuerdo de colaboración firmado entre la Revista Teoría y Realidad Constitucional y el Centro de Estudios de Partidos de la UNED para la publicación de trabajos de investigación sobre el régimen constitucional de los partidos políticos. Este trabajo se publica en el marco del Proyecto DER 2017-84733-R: Partidos políticos, origen, función y revisión de su estatuto constitucional.

2 Comisión Europea para la democracia a través del Derecho (Comisión de Venecia), Informe conjunto de la Comisión de Venecia y de la Dirección de la Sociedad de la Información y lucha contra la delincuencia de la Dirección General de Derechos Humanos y Estado de Derecho (DGI) sobre Tecnologías Digitales y Elecciones, aprobado por la Comisión de Venecia en su 119ª Sesión plenaria, 21-22 de junio de 2019 (CDL-AD(2019)016) (En adelante, Informe de la Comisión de Venecia sobre Tecnologías Digitales y Elecciones, 2019. Disponible on line: http:// www.cepc.gob.es/docs/default-source/comisionveneciadoc/cdl-ad(2019)016-e.pdf?sfvrsn=0), Apdo. 4. Vid., 
La comunicación con el electorado es la esencia de todo proceso democrático. Los avances tecnológicos posibilitan que la comunicación política adquiera dimensiones masivas, pero, al mismo tiempo, la utilización de mensajes de texto, correos electrónicos, redes sociales o llamadas automatizadas provocan que el contacto se vuelva más directo. ${ }^{3}$ Es habitual que los partidos políticos adapten sus mensajes al público y tengan en cuenta sus intereses específicos con el fin de conseguir el mayor número de votos posible y, por ello, es lógico que estudien cómo utilizar los datos personales de los electores para llegar a ellos de una forma más personalizada, más rentable y con más posibilidad de éxito para sus intereses. ${ }^{4}$ Esto ha provocado que los datos personales, la información personal, se conviertan en la nueva moneda de la Revolución digital que vivimos y que los diferentes actores sociales, políticos y económicos quieran tener acceso a los mismos. ${ }^{5}$

también, el Informe Digital Mundial del 2019 („Digital 2019«) —elaborado por la plataforma Hootsuite y We are social, agencia creativa inglesa- Disponible on line: https://wearesocial.com/global-digital-report-2019-, que indica que de un total de 7.676 millones de habitantes en el mundo, aproximadamente 4.388 millones son usuarios de Internet (lo que representa el $57 \%$ de la población total) y el número de nuevos usuarios de Internet crece más de un millón de personas al día.

3 Orientaciones de la Comisión relativas a la aplicación de la legislación sobre protección de datos de la Unión en el contexto electoral (Elecciones libres y limpias), aprobadas por la Comisión Europea en la reunión de dirigentes en Salzburgo los días 19 y 20 de septiembre de 2018 (COM(2018) 638 final) (En adelante, Documento de Orientación de la Comisión Europea sobre Elecciones libres y limpias, 2018. Disponible on line: https://eur-lex. europa.eu/legal-content/ES/TXT/PDF/?uri=CELEX:52018DC0638\&from=es). Vid., también, Dictamen 10/2018, del Supervisor Europeo de Protección de Datos, sobre el Paquete de la Comisión relativo a unas elecciones europeas libres y justas, de 17 de diciembre de 2018 (Disponible on line: https://edps.europa.eu/sites/edp/ files/publication/18-12-18_opinion_on_election_package_en.pdf).

$4 \mathrm{Si}$ bien es una cuestión que ha levantado polémica en la actualidad, el tema ya había sido tratado por la doctrina con anterioridad, destacando el magnífico trabajo de la Profesora García MaHAmut, R., «Partidos políticos y derecho a la protección de datos en campaña electoral: tensiones y conflictos en el ordenamiento español», Teoría y Realidad Constitucional, no 35, 2015, pp. 309-338 (pp. 309-310, 325 y 332), quien resalta el peligro de la elaboración de grandes bases de datos de perfiles ideológicos por parte de los partidos políticos. Al respecto, vid. también, citado por la mencionada autora, HowArD, P.N. / KREISs, D., «Political parties and voter privacy: Australia, Canada, the United Kingdom and United States in comparative perspective», First Monday, Vol. 15, n 12-6, 2010; y BennetT, C.J. / BAyley, R.M., "Canadian federal political parties and personal privacy protection: A comparative analysis», Estudio elaborado para la Oficina del Comisionado de Privacidad de Canada, de 28 de marzo de 2012 (Disponible on line: https://www.priv.gc.ca/ media/1756/pp_201203_e.pdf). Vid., también, sobre la protección de datos en campaña electoral, GARCíA Maнamut, R., «Elecciones y Protección de Datos: Los grandes desafíos para la Unión Europea», en Rallo Lombarte, A. / García Mahamut, R., (Ed.), Hacia un nuevo derecho europeo de protección de datos, Tirant lo Blanch, Valencia, 2015, pp. 499 y ss.; y Rubio NúñEZ, R., «Nuevas tendencias de regulación del uso de las nuevas tecnologías en campaña electoral», en BArrat I Esteve, J. / Fernández Riveira, R. (Coords.), Derecho de sufragio y participación ciudadana a través de las nuevas tecnologías, Thomson Reuters, Pamplona, 2011, pp. 313-333.

5 Algunas empresas de análisis de datos se especializan en analizar a los sujetos en base a cinco rasgos de personalidad plasmados en las redes sociales y conocidos como los «Cinco Grandes» («Big Five», o por sus siglas en inglés OCEAN: openness, conscientiousness, extroversion, agreeableness, neuroticism (sinceridad, concienciación, extraversión, satisfacción, grado de influencia)). En relación con OCEAN, vid. GrassegGer, H. / Krogerus, M., «The Data That Turned the World Upside Down», News. Stanford Public Policy Program, de 28 de enero de 2017 (Disponible on line: https://publicpolicy.stanford.edu/news/data-turned-world-upside-down); POLONSKI, V.W., 
Internet, las redes sociales, el big data o los grandes sistemas de análisis de datos y la inteligencia artificial hacen posible la recopilación, combinación, análisis y almacenamiento indefinido de grandes volúmenes de datos, así como la identificación de todos y cada uno de los aspectos de la vida de una persona, desde su mera descripción física hasta sus gustos, preferencias y deseos. ${ }^{6}$ Los sujetos pueden participar en la toma de decisiones que les afectan de una forma hasta ahora inimaginable y conectados con cualquier parte del mundo pueden hacerse oir directamente por sus dirigentes políticos, pero todos sus pasos en Internet, sus gustos y acciones se registran automáticamente y van dejando lo que se denominan «migas de pan digitales» («digital breadcrumbs») que van a permitir predecir su personalidad y comportamiento, ${ }^{7}$ realizar un perfilado de los mismos.

Lo que sucede es que cuando el acceso a nuestra información personal se produce por quienes nos van a gobernar, al margen de nuestra capacidad de control o conocimiento, saltan las alarmas por la posible manipulación de nuestra voluntad y de nuestra capacidad de decidir. Un claro ejemplo del impacto de esta transformación digital vulnerando la privacidad de los sujetos en un proceso electoral se puso se manifiesto con el conocido caso Cambridge Analityca, utilizando información personal de los votantes sin cumplir con las exigencias y garantías previstas en la normativa de protección de datos o en la electoral con el fin de distorsionar el debate político y manipulando la orientación de voto de los votantes gracias a la información que se conocía de los mismos, ${ }^{8}$ incluso de manera personalizada gracias a las técnicas de perfilado personalizado basadas en estrategias de marketing (también conocidas como microtargeting).?

«How artificial intelligence conquered democracy», The Conversation, de 8 de agosto de 2017 (Disponible on line: https://theconversation.com/how-artificial-intelligence-conquered-democracy-77675).

6 García SANZ, R.M., «Tratamiento de datos personales de las opiniones políticas en el marco electoral: todo en interés público», Revista de Estudios Políticos, n 183, 2019, pp. 129-159 (p. 148).

7 Así lo puso de manifiesto el Dictamen 3/2018, del Supervisor Europeo de Protección de Datos, sobre La manipulación en línea y los datos personales, de 19 de marzo de 2018 (En adelante, Dictamen 3/2018 SEPD. Disponible on line: https://edps.europa.eu/sites/edp/files/publication/18-03-19_online_manipulation_ en.pdf), exigiendo medidas para hacer cumplir los principios de protección de datos y, en particular, la información detallada a los interesados, la limitación de la finalidad, la minimización de los datos y su almacenamiento.

8 Vid., sobre este asunto, la información publicada en el New York Times, de 19 de marzo 2018, en la sección de opinión, «Facebook’s Surveillance Machine». Y para la posición de la UE ante este escándalo, véase la Resolución del Parlamento Europeo, de 25 de octubre de 2018, sobre La utilización de los datos de los usuarios de Facebook por parte de Cambridge Analytica y el impacto en la protección de los datos (2018/2855(RSP)). Estudios, como los del prestigioso investigador Robert Epstein, manifiestan el poder manipulador en las preferencias electorales y de los rankings por parte de los motores de búsqueda (lo que se conoce como Efecto Manipulador de los Motores de Búsqueda, Search Engine Manipulation Effect, por sus siglas en inglés, SEME), en tanto que las páginas web que favorecen a un candidato tienen un impacto directo en las opiniones de los indecisos. Así lo puso de manifiesto el investigador citado, Epstein, R., «Why Google Poses a Serious Threat to Democracy, and How to End That Threat», Intervención ante el Senado de Estados Unidos el 16 de junio de 2019 (Disponible on line en: https://www.judiciary.senate.gov/imo/media/doc/Epstein\%20Testimony.pdf).

9 En el Informe de la Comisión de Venecia sobre Tecnologías Digitales y Elecciones, 2019, Apdo. 77, se ponía de manifiesto que aunque el perfilado de los sujetos «inicialmente se percibió como una técnica 
Debemos asegurar la privacidad de los electores para garantizar el principio de igualdad de oportunidades en los procesos electorales, evitando el peligro de una manipulación de la opinión pública, ${ }^{10}$ y devolviendo «la confianza al público en la limpieza del proceso electoral», ${ }^{11}$ rompiendo con la creciente desafeción ciudadana. ${ }^{12} \mathrm{La}$ tecnología tiene sus beneficios, pero también sus peligros y debemos buscar el equilbrio entre el uso de la información y el respeto por la dignidad y los derechos de los ciudadanos. Esto es esencial para la salud de nuestras democracias.

A nivel internacional, comunitario y en nuestro entorno europeo son numerosas las iniciativas tendentes a regular el tratamiento de datos personales por parte de candidatos y partidos políticos, y cuestiones relacionadas con el contenido on line y las campañas de desinformación con el fin de proteger el debate político y la formación de la opinión pública y, por tanto, el buen desarrollo de los procesos democráticos. ${ }^{13}$ Por esta vía han apostado las Autoridades de

utilizada en un contexto empresarial y de marketing, los recientes acontecimientos demuestran que la elaboración de perfiles también se aplica en los procesos electorales».

10 Informe de la Comisión de Venecia sobre Tecnologías Digitales y Elecciones, 2019, Apdo. 38; y García Maнamut, R., «Partidos políticos y... », op. cit., pp. 309-310 y 319, quien se refiere a los principios de objetividad, neutralidad política, transparencia o igualdad de armas y se refiere a estudios que cuantifican los efectos de las tecnologías en la comunicación política y en los partidos políticos, como LATIMER, CH.P., «Utilizing the Internet as a Campaign Tool», Journal of Information Technology E Politics, 4:3, 2008, pp. 81-95; Gibson, R.K. / Mcallister, I., «Does Cyber-Campaigning Win Votes? Online Communication in the 2004 Australian Election», Journal of Elections, Public Opinion E Parties, 16:3, 2006, pp. 243-263; GIBSON, R. / WARD., S, «Parties in the Digital age. A review article», Representation, 45:1, 2009, pp. 87-100; Aragón, P. y otros, «Communication dynamics in twitter during political campaigns: The case of the 2011 Spanish national election», PolicyEInternet, Vol 5, n 2, 2013, pp. 183-206; y LARsson, A.O., «Online, all the time? A quantitative assessment of the permanent campaign on Facebook», New Media E Society, Vol. 18(2), 2016, pp. 274-292.

11 En este sentido, vid. la Resolución n ${ }^{\circ}$ 3, de la Conferencia de Ministros de Justicia del Consejo de Europa, de 26 de noviembre de 2010, sobre La protección de datos y la privacidad en el tercer milenio (MJU-30 (2010) RESOL. 3 E), que señalaba que la percepcion de las ventajas de Internet se podía ver ensombrecida por la sensación de estar bajo vigilancia continua con el efecto que esto tendría sobre el libre ejercicio de los derechos y libertades de los ciudadanos (Disponible on line: https://rm.coe.int/CoERMPublicCommonSearchServices/DisplayDCTMContent?documentId=0900001680694515). Y, también, el ya citado Documento de Orientación de la Comisión Europea sobre Elecciones libres y limpias, 2018; y con esta idea, sobre la crisis institucional existente, GARCía SANZ, R.M., «Tratamiento de datos...», op. cit., pp. 138-139, con referencia a Torres Del Moral, A., La opinión pública y su tratamiento jurisprudencial. Constitución y desarrollo político, Tirant lo Blanch, Valencia, 2013, pp. 1361-1396.

12 Bustos Gisbert, R., Calidad democrática. Reflexiones constitucionales desde la teoría, la realidad y el deseo, Marcial Pons, Madrid, 2017, Cap. III: «la crisis de los intermediarios en la participación política — partidos y medios de comunicación- supone también la crisis de la formación de la opinión pública».

13 Así, por ejemplo, en Alemania, a principios de 2018, se aprobó una Ley obligando a los intermediarios de Internet, como Facebook, Instagram, Twitter o YouTube, a eliminar rápidamente, en caso de denuncia, cualquier contenido tipificado como ilegal (Gesetz zur Verbesserung der Rechtsdurchsetzung in sozialen Netzwerken (Netzwerkdurchsetzungsgesetz, NetzDG)). En noviembre de 2018, de forma más específica, en Francia se aprobó una Ley para combatir la manipulación de la información durante los períodos electorales (Loi $n^{\circ} 20181202$ relative à la lutte contre la manipulation de l'information). También en 2018, en junio, en el Reino Unido, la Comisión Electoral Británica pidió una mayor transparencia para los votantes con respecto a la práctica de las campañas electorales digitales, haciendo recomendaciones sobre la 
Protección de Datos, que han elaborado Normas o Directrices sobre el tratamiento de datos personales con fines políticos. ${ }^{14}$ Todos estos documentos coinciden en la necesidad de garantizar la aplicación de la normativa de protección de datos en el contexto electoral. ${ }^{15}$

En esta línea, en nuestro ordenamiento jurídico, con el fin de regular el uso de los medios tecnológicos y los datos personales en las actividades electorales, la Ley Orgánica 3/2018, de Protección de Datos Personales y Garantía de los Derechos Digitales (LOPDGDD) — más allá de garantizar de forma novedosa nuevos derechos digitales e introducir en nuestro ordenamiento jurídico las novedades diseñadas por el Reglamento (UE) 2016/679 General de Protección de Datos (RGPD) — modificó, concretamente en su Disposición Final Tercera, la Ley Orgánica 5/1985, del Régimen Electoral General (LOREG), y para el caso que aquí interesa, introdujo el artículo 58.bis). ${ }^{16} \mathrm{~A}$ pesar de que la

responsabilidad, el gasto y la transparencia (Digital campaigning. Increasing transparency for voters). Con detalle sobre estas prácticas, vid. Informe de la Comisión de Venecia sobre Tecnologías Digitales y Elecciones, 2019, Apdos. 99-106.

14 A nivel internacional, vid. la Resolucion sobre el Uso de Datos personales para la Comunicación política, aprobada en la $27^{\text {a }}$ Conferencia Internacional de Autoridades de Protección de Datos y Privacidad, celebrada del 14 al 16 de septiembre de 2005, en Montreux (Suiza) (Disponible on line: https://icdppc.org/ wp-content/uploads/2015/06/political_communication_resolution-spanish.pdf), Considerandos $5^{\circ}$ y $6^{\circ}$. A nivel europeo, partiendo del ya citado Dictamen 3/2018 SEPD, podemos mencionar también que en marzo de 2014 el Garante italiano aprobó unas Normas sobre el tratamiento de datos personales por los partidos políticos, destacando la prohibición general de utilizar con fines de comunicación política los datos personales que se hacen públicos en Internet, como las redes sociales o los foros, si estos datos se habían recogido con otros fines («Provvedimento in materia di trattamento di dati presso i partiti politici e di esonero dall'informativa per fini di propaganda elettorale»). Unos años más tarde, la CNIL francesa, en noviembre de 2016, aprobó unas Directrices sobre comunicación política, subrayando que la elaboración de perfiles del electorado sólo sería legítima si contaba con el consentimiento de los sujetos perfilados ( Communication politique: quelles sont les règles pour l'utilisation des données issues des réseaux sociaux?»). La siguiente en actuar fue la Oficina del Comisionado de Información del Reino Unido, en abril de 2017, recogiendo en una Guía sobre las campañas políticas, las directrices sobre la posibilidad de analizar los datos personales de los electores en las campañas electorales ( Guidance on political campaigning»), o los Informes de 10 de julio de 2018 ( «Investigation into the use of data analytics in political campaigns - Investigation update» y «Democracy Disrupted? Personal information and political influence»). A nivel comunitario, la Comisión Europea presentó en septiembre de 2018 la «Guía sobre la aplicación de la normativa europea de protección de datos en el contexto electoral». En España debemos citar el Informe jurídico AEPD 210070/2018, de 19 de diciembre, sobre Tratamiento de datos de opiniones políticas por los partidos políticos (en adelante, Informe jurídico AEPD 210070/2018), y la Circular 1/2019, de 7 de marzo, de la AEPD, sobre el tratamiento de datos personales relativos a opiniones políticas y envío de propaganda electoral por medios electrónicos o sistemas de mensajería por parte de partidos políticos, federaciones, coaliciones y agrupaciones de electores al amparo del artículo 58 bis de la LOREG (en adelante, Circular 1/2019 AEPD).

15 Memoria del Análisis de impacto normativo de la Circular 1/2019 AEPD, de 25 de enero de 2019.

16 Artículo 58 bis) LOREG: «Utilización de medios tecnológicos y datos personales en las actividades electorales. 1. La recopilación de datos personales relativos a las opiniones políticas de las personas que lleven a cabo los partidos políticos en el marco de sus actividades electorales se encontrará amparada en el interés público únicamente cuando se ofrezcan garantías adecuadas. 2. Los partidos políticos, coaliciones y agrupaciones electorales podrán utilizar datos personales obtenidos en páginas web y otras 
LOPDGDD fue aprobada por una amplia mayoría parlamentaria y con el beneplácito de todos los partidos políticos representados en la Cámara Baja, la publicación de la modificación de la LOREG levantó un acalorado debate, ${ }^{17}$ manifestaciones ciudadanas en contra y numerosos títulares de prensa. ${ }^{18}$ Todo ello acabó con la presentación, por parte del Defensor del Pueblo, de un recurso de inconstitucionalidad solicitando la declaración de inconstitucionalidad del primer apartado del art. 58.bis) LOREG al apreciar que dicho artículo permitía la posibilidad de recopilar información sensible de los ciudadanos, como son sus opiniones políticas, sin que éstos hubieran consentido a ello y sin que se tomaran las debidas y adecuadas garantías, amparándose en un genérico interés público. ${ }^{19} \mathrm{El}$ Tribunal Constitucional vino a confirmarlo declarando la inconstitucionalidad del primer apartado del art. 58.bis) LOREG en su Sentencia 76/2019.

Así las cosas, conforme al actual texto de la LOREG, los partidos políticos no podrán recopilar las opiniones políticas que los ciudadanos expresen en Internet sin las garantías adecuadas, pero la posibilidad de recopilar opiniones políticas sigue presente en el RGPD y en la práctica. Existe una evidente y, más que justificada, preocupación. Esto nos lleva a la necesidad de regular la presencia tecnológica en las campañas electorales,$^{20} \mathrm{y}$, por lo tanto, garantizar la aplicación de la normativa de protección de datos en el contexto electoral.

fuentes de acceso público para la realización de actividades políticas durante el periodo electoral. 3. El envío de propaganda electoral por medios electrónicos o sistemas de mensajería y la contratación de propaganda electoral en redes sociales o medios equivalentes no tendrán la consideración de actividad o comunicación comercial. 4. Las actividades divulgativas anteriormente referidas identificarán de modo destacado su naturaleza electoral. 5. Se facilitará al destinatario un modo sencillo y gratuito de ejercicio del derecho de oposición». Este artículo tiene su origen en la Enmienda de adición n $n^{\circ} 331$ presentada por el Grupo Parlamentario Socialista (Boletín Oficial de las Cortes Generales, Serie A, nº 13-2, de 18 de abril de 2018), que justificó su inclusión en base al Considerando 56 RGPD y con el fin de evitar casos como el de Cambridge Analityca. La enmienda no fue aprobada en su totalidad, omitiéndose íntegramente su segundo apartado: «2. Cuando la difusión de propaganda electoral en redes sociales o medios equivalentes se base en la elaboración sistemática y exhaustiva de perfiles electorales de personas físicas, deberá realizarse una previa evaluación de impacto relativa a la protección de datos personales en los términos previstos en el artículo 35 del Reglamento (UE) 2016/679. Dicha difusión no podrá realizarse cuando se identifique un alto riesgo para los derechos y libertades de las personas y no se adopten las medidas necesarias para impedirlo. Quedan prohibidas las actividades de propaganda electoral basadas en la elaboración de perfiles electorales en redes sociales o equivalentes cuando no se informe a sus destinatarios sobre su finalidad, la identidad del responsable o la entidad contratada para su realización y los criterios de selección». En palabras de López MARTínez, el texto finalmente aprobado «fue algo más suave (aunque también, en mi opinión, demasiado parco e impreciso) que el propuesto vía enmienda» (López MartíNEZ, J., «Partidos políticos y datos personales de los ciudadanos. ¿Qué pueden usar y para qué?», SEPIN, marzo 2019 (Referencia SP/DOCT/81982)).

17 Adsuara Varela, B. / Martínez Martínez, R., «Debate sobre el nuevo artículo 58 bis de la LOREG», La Ley Privacidad, nº 1, Diario La Ley (on line), mayo 2019.

18 Citando algunos titulares del momento, vid. López Martínez, J., «Partidos políticos y... », op. cit. .

19 Recurso de inconstitucionalidad n. ${ }^{\circ}$ 1405-2019, contra el artículo 58 bis. 1 de la LOREG, incorporado a ésta por la disposición final tercera, punto dos, de la LOPDGDD.

20 Adsuara Varela, B. / Martínez Martínez, R., «Debate sobre el...», op. cit. . 


\section{TRANSFORMACIÓN DIGITAL, PARTIDOS POLÍTICOS, DATOS PERSONALES Y ELECCIONES}

\section{Partidos políticos y datos personales}

Nuestro texto constitucional nos dice en su artículo 6 que los partidos políticos son un instrumento fundamental para la participación política, contribuyendo a la manifestación de la voluntad popular y a la formación de la opinión pública, exigiéndoles un funcionamiento democrático. ${ }^{21} \mathrm{Y}$, por otro lado, para lo que aquí nos interesa, se reconoce el derecho fundamental a la protección de datos personales en su artículo 18.4, limitando el uso de la informática. ${ }^{22}$ En este último caso, sin detenernos en su reconocimiento o en su evolución y desarrollo normativo, recordamos que en la actualidad regulan el tratamiento de datos personales en España tanto el ya citado RGPD como la ya también citada LOPDGDD.

Los partidos políticos, así como todos los agentes que intervienen en un proceso electoral, en tanto tratan datos personales, o utilizan perfiles de los votantes, ${ }^{23}$ se encuentran sometidos a los requisitos contenidos tanto en el RGPD como a los previstos en la LOPDGDD. Los datos personales tratados por los partidos políticos pueden ir desde los nombre y apellidos de los afiliados hasta su orientación o ideología política, así como los relacionados con los procesos electorales previstos en la LOREG y en las normas electorales de desarrollo. ${ }^{24}$

21 La Recomendación (UE) 2018/234, con vistas a reforzar el carácter europeo y el desarrollo eficiente de las elecciones de 2019 al Parlamento Europeo (DOUE L 45, de 17 de febrero) reconoce igualmente el papel de los partidos políticos en la formación de la conciencia política, el fomento de la participación de los votantes y la expresión de la voluntad de los ciudadanos.

22 Por todos, la STC 292/2000.

23 Así, por ejemplo, la elaboración de perfiles debe cumplir con la exigencia de ser comunicada a los sujetos objeto del mismo, máxime si tiene consecuencias en sus derechos de participación política. Al respecto, vid. arts. 13.2.f) y 22 RGPD (concretamente, art. 22.4), así como las Directrices, del Grupo de Trabajo del Art. 29, sobre Decisiones individuales automatizadas y elaboración de perfiles a los efectos del Reglamento 2016/679, aprobadas 3 de octubre de 2017, y revisadas por última vez el 6 de febrero de 2018 (WP251 rev.01).

24 Según el art. 4.1) RGPD un dato personal es «toda información sobre una persona física identificada o identificable («el interesado»); se considerará persona física identificable toda persona cuya identidad pueda determinarse, directa o indirectamente, en particular mediante un identificador, como por ejemplo un nombre, un número de identificación, datos de localización, un identificador en línea o uno o varios elementos propios de la identidad física, fisiológica, genética, psíquica, económica, cultural o social de dicha persona». Recordamos aqui, como dijera la STC 292/2000 (FJ $7^{\circ}$ ), que «el derecho fundamental a la protección de datos amplía la garantía constitucional a aquellos de esos datos que sean relevantes para o tengan incidencia en el ejercicio de cualesquiera derechos de la persona, sean o no derechos constitucionales y sean o no relativos al honor, la ideología, la intimidad personal y familiar o cualquier otro bien constitucionalmente amparado» y, por ello, los datos de carácter personal amparados «son todos aquellos que identifiquen o permitan la identificación de la persona pudiendo servir para la confección de su perfil ideológico, racial, sexual, económico o de cualquier otra índole, o que sirvan para cualquier otra utilidad que en determinadas circunstancias constituya una amenaza para el individuo». 
No obstante, debemos tener en cuenta aquí dos circunstancias: en primer lugar, que entre los datos que pueden tratar los partidos políticos se encuentran los relacionados con la ideología política, que constituye lo que se conoce como un dato especialmente protegido o categoría especial de dato personal, ${ }^{25}$ cuyo tratamiento está prohibido, salvo en determinados supuestos. ${ }^{26} \mathrm{Y}$, por otro lado, en segundo lugar, que en nuestro ordenamiento jurídico la propia normativa de protección de datos señala expresamente que la misma no será de aplicación a determinados ámbitos, entre los que se incluyen «los tratamientos realizados al amparo de la legislación orgánica del régimen electoral general», ${ }^{27}$ como es el caso, por ejemplo, del tratamiento de los datos personales contenidos en el censo electoral, que se regirá por las disposiciones específicas de la LOREG y de los Reales Decretos que lo desarrollan. ${ }^{28}$

Así las cosas, en el caso específico de los partidos políticos, más allá del supuesto que permite el tratamiento de datos personales de sus afiliados, lo que identifica claramente su ideología ${ }^{29}$ se podrían atender varios supuestos en los que los partidos políticos podrían tratar los datos personales de sus electores levantando la prohibición general.

El RGPD y la LOPDGDD señalan expresamente que este tipo de datos sensibles podrán ser tratados si existe el consentimiento explícito del titular de los datos $\mathrm{y}$, además, ${ }^{30}$ si el titular de los datos los ha hecho manifiestamente públi$\cos ,{ }^{31} \mathrm{o}$ bien, si existe un interés público esencial, que deberá tener una base legítima (que en el caso de España será «una norma con rango de ley»), ser proporcional al objetivo perseguido y, además, «establecer medidas adecuadas y específicas» que protejan al titular de los datos. ${ }^{32}$ En relación con este último supuesto, por razones de interés público, el Considerando 56 RGPD señala que los partidos

25 Art. 9 RGPD y art. 9 LOPDGDD. Entre los reenvíos que el RGPD hace a los Estados se encuentra el desarrollo de las circunstancias en las que pueden tratarse estas categorías especiales de datos (Considerando 10 RGPD). Así lo reconoce también la STC 76/2019 al señalar que «de manera expresa el RGPD ha reconocido a los Estados miembros «margen de maniobra» a la hora de especificar sus normas» $\left(\mathrm{FJ} 4^{\circ}\right)$.

26 Art. 9.1 RGPD y art. 9.1 LOPDGDD.

27 Art. 2.3 LOPDGDD.

28 Según el art. 31.1 LOREG en el censo están inscritos aquellos sujetos que pueden ser electores, y es el art. 32.1 LOREG el que además de establecer la obligatoriedad de estar inscritos en el mismo señala que: «Además del nombre y los apellidos, único dato necesario para la identificación del elector en el acto de la votación, sin perjuicio de lo dispuesto en el artículo 85, se incluirá entre los restantes datos censales el número del Documento Nacional de Identidad». Más allá del citado art. 85 LOREG, que se refiere a la acreditación del derecho a votar, pero no hace referencia a los datos contenidos en el censo, el art. 41.1 LOREG indica que «Por real decreto se regularán los datos personales de los electores, necesarios para su inscripción en el censo electoral, así como los de las listas y copias del censo electoral». Por lo tanto, deberemos acudir, básicamente, al RD 1799/2003, por el que se regula el contenido de las listas electorales y de las copias del censo electoral.

29 Art. 9.2.d) RGPD, siempre y cuando dicho tratamiento se haga «en el ámbito de sus actividades legítimas y con las debidas garantías».

30 Art. 9.2.a) RGPD y 9.1 LOPDGDD.

31 Art. 9.2.e) RGPD.

32 Art. 9.2.g) RGPD y 9.2 LOPDGDD. 
políticos podrán tratar datos personales relacionados con las opiniones políticas de las personas «en el curso de las actividades electorales» y para «el funcionamiento del sistema democrático», exigiéndose además el establecimiento de «las garantías adecuadas». ${ }^{33}$

En este orden de cosas, teniendo en cuenta, también, que estamos hablando de comunicación electoral y de mensajes electorales, y de su posible comunicación electrónica, debemos tener en cuenta la normativa europea y nacional que marca las reglas a seguir en el caso del tratamiento de la información on line y en relación con el rastreo del comportamiento en línea a través de las conocidas cookies o, en relación con el envío de mensajes publicitarios de propaganda electoral, ${ }^{34}$ teniendo en cuenta que en nuestro ordenamiento la misma no se considera «publicidad» o actividad comercial. ${ }^{35}$

Partiendo del hecho de que los partidos políticos podrán tratar datos personales de los electores, debemos analizar si se cumplen las anteriores circunstancias. Pero debemos hacerlo teniendo en cuenta lo previsto, con carácter especial, en la legislación electoral, esto es, en la LOREG y en la normativa que la desarrolla, centrándonos en los procesos electorales, dado que es aquí donde nuestro Tribunal Constitucional se ha pronunciado con su Sentencia 76/2019, marcando cómo deben ser las pautas para evitar un uso indebido de los datos personales de los ciudadanos por parte de los partidos políticos en los procesos electorales, ${ }^{36} \mathrm{y}$, concretamente, cuando lo hacen usando medios tecnológicos.

33 Martínez Martínez, R. «Partidos, algoritmos y campañas electorales», Telos, n 110, pp. 130 135 (p. 133), para quien esta habilitación específica demuestra que es «lógico considerar que los partidos para cumplir con su función constitucional puedan tratar datos personales bajo ciertas condiciones».

34 Directiva 2002/58/CE del Parlamento Europeo y del Consejo, de 12 de julio, relativa al tratamiento de los datos personales y a la protección de la intimidad en el sector de las comunicaciones electrónicas (Directiva sobre la Privacidad y las Comunicaciones Electrónicas). En la actualidad se está negociando un Reglamento sobre Privacidad y comunicaciones electrónicas, el conocido como Reglamento e-Privacy. Vid., también, Directiva 2000/31/CE, del Parlamento Europeo y del Consejo, de 8 de junio, relativa a determinados aspectos de los servicios de la sociedad de la información, en particular, el comercio electrónico en el mercado interior (Directiva sobre el comercio electrónico). Asimismo, tener en cuenta la Ley 34/2002, de Servicios de la Sociedad de la Información y de Comercio Electrónico (LSSI).

35 Art. 58.bis). 3 LOREG; y art. 21 LSSI, sobre Prohibición de comunicaciones comerciales realizadas a través de correo electrónico o medios de comunicación electrónica equivalentes. Sobre esta cuestión, vid. García Mahamut, R., «Partidos políticos y... », op. cit., p. 326, quien recuerda — como ha señalado la AEPD en el Procedimiento sancionador $N^{\circ}$ PS/00681/2013, Resolución R/00591/2014, p. 4- que en España, a diferencia del resto de nuestros países vecinos, como es el caso del Reino Unido, el spam político no se encuentra prohibido en campaña electoral porque no se considera spam.

36 Sin detenernos en este trabajo, por su extensión, más allá del pronunciamiento de la STC 76/2019, nos remitimos aquí al excelente trabajo ya citado de GARCía MAHAMUT, R., «Partidos políticos y... », op. cit., p. 314, quien recoge los numerosos conflictos existentes, especialmente, en relación con el uso ilícito del censo. Desde la aprobación del RGPD en 2016, la mayoría de las sanciones están relacionadas con la utilización de datos personales sin consentimiento de los afectados para fines de propaganda electoral mediante actividades como la copia indebida del censo, el envío de propaganda vía sms o a cuentas de correo electrónico personal, tanto a ciudadanos como a funcionarios, o sin poner en copia oculta las direcciones de correos masivos; aunque también se utilizaron indebidamente los datos del censo para ubicar a dos personas y acusarlas de favoritismo en unas concesiones municipales. Pero debemos destacar, por su cuantía, la SAN de 20 de 


\section{Transformación digital y procesos electorales}

Las tecnologías digitales han transformado no sólo las campañas políticas, sino que, derivado de dicha transformación, también han cambiado la forma en la que la voluntad del pueblo se traduce en sus votos. ${ }^{37}$ El debate democrático se ha trasladado en gran medida al ámbito virtual, a Internet. ${ }^{38} \mathrm{La}$ posibilidad de los operadores de Internet de procesar la información de sus usuarios y crear perfiles muy precisos de los mismos, además de predecir sus preferencias e incluso dirigirse a ellos con datos y publicidad individualizados, consiguen promover o desalentar determinadas conductas, entre las que se encuentra la decisión de voto. ${ }^{39}$

En este orden de cosas, teniendo en cuenta que en todo proceso democrático la campaña electoral se convierte en la «clave de la bóveda del régimen democrático» ${ }^{40}$ y que las nuevas tecnologías van a alterar los principios que deben regir la misma (libre concurrencia, competitividad e igualdad de oportunidades), se hacía, y hace, necesario regular el proceso en un entorno digital. ${ }^{41}$ Pero no sólo es en la campaña o periodo electoral donde las tecnologías influyen en el proceso de formación de la voluntad de los ciudadanos, sino que no podemos perder de vista que los partidos políticos pueden utilizar los avances tecnológicos de forma permanente en su función de formación de la opinión pública. ${ }^{42}$

diciembre de 2018, que desestimó el recurso contra la Resolución de la AEPD, de 5 de abril de 2016, por la que se sancionaba con unos 200.000 euros a las entidades ANC y ÒMNIUM CULTURAL por la realización de lo que denominaron Gigaencuesta identificando la intención de voto de los encuestados para poder dirigirse posteriormente a ellos con el fin de incrementar su participación en la consulta de octubre.

37 Sin detenernos en el tema, no podemos olvidar las cuestiones relacionadas con el voto electrónico. Por todos, Barrat i Esteve, J., «El voto electrónico y sus dimensiones jurídicas: entre la ingenua complacencia y el rechazo precipitado», en BARRAT i ESTEVE, J., El votor electrónico y sus dimensiones jurídicas, Iustel, Madrid, 2016, pp. 13-18.

38 Informe de la Comisión de Venecia sobre Tecnologías Digitales y Elecciones, 2019, Apdos. 46 y 47

39 El Prof. de la Universidad de Harvard, Jonathan ZitTrain, manifestó que dada la enorme cantidad de información que Facebook recopila de sus usuarios podría, fácilmente, enviar mensajes sólo a personas que apoyaran a un determinado partido o candidato en particular, sin que nadie supiera que ésto ha ocurrido y sin dejar rastro de ello. Vid. ZitTrain, J., «Facebook Could Decide an Election Without Anyone Ever Finding Out», The New Republic, 2 de junio de 2014 (Disponible on line en: https://newrepublic.com/article/117878/ information-fiduciary-solution-facebook-digital-gerrymandering).

40 García Mahamut, R., «Partidos políticos y... », op. cit., p. 321. Vid., también, Resolucion sobre el Uso de Datos personales para la Comunicación política, aprobada en la $27^{\text {a }}$ Conferencia Internacional de Autoridades de Protección de Datos y Privacidad, celebrada del 14 al 16 de septiembre de 2005 en Montreux (Suiza), donde se manifestó que «la comunicación política es un instrumento fundamental de la participación de los ciudadanos, de las fuerzas políticas y de los candidatos en la vida democrática y reconociendo la importancia de la libertad del discurso político como un derecho fundamental».

41 García SAnZ, R.M., «Tratamiento de datos...», op. cit., p. 154, quien habla de una «nueva versión» en los medios electrónicos.

42 No podemos olvidar que la garantía de unas elecciones libres no es sólo una exigencia constitucional de nuestro Estado. En el Consejo de Europa, el Protocolo I del CEDH en su artículo 3 grantíza el derecho a unas elecciones libres, siendo la equidad y la transparencia requisitos esenciales de dicho derecho. De la misma forma, el art. 39 CDFUE garantiza el derecho de sufragio bajo la premisa de unas elecciones libres. 
El entorno digital, Internet, puede facilitar la formación de esa opinión pública, donde todo el mundo puede escuchar y ser escuchado, fomentándose asî el pluralismo político; y también permite una comunicación más rápida y fluida entre ciudadanos y partidos. Pero es también evidente que la Revolución digital trae desde fenónemos de desinformación asociados, como las conocidas fake news o el uso de cuentas falsas hasta la utilización y manipulación de datos personales sin consentimiento y, en muchos casos, sin conocimiento, de sus titulares ${ }^{43}$ lo que «han provocado manipulación, confusión y falsificación de la opinión publica, cuya centralidad en el funcionamiento democrático está fuera de dudas». ${ }^{44}$ Esta falta de transparencia tiene evidentes consecuencias negativas para la imparcialidad y la libertad del proceso de toma de decisiones. ${ }^{45}$ Esta manipulación a través de algoritmos no busca ya controlar a los sujetos, sino manipularlos de forma interesada, modificando la voluntad electoral. ${ }^{46}$ Es esencial garantizar la neutralidad electoral, máxime si para dicha alteración se están empleando las nuevas tecnologías. ${ }^{47}$

En nuestro ordenamiento jurídico la regulación de los procesos electorales, de la campaña electoral, de la entrega de la copia del censo electoral a los partidos políticos, de la propaganda electoral, o del uso de los medios tecnológicos por parte de los partidos políticos, se recoge con carácter general en la LOREG. ${ }^{48}$

Hasta la reforma que la LOPDGDD introdujo en la LOREG, la comunicación de los partidos políticos con sus electores tenía como base los datos recogidos en el censo electoral. Esto es, los partidos políticos (más allá del tratamiento de datos personales de sus afiliados) sólo podían tratar los datos personales de los electores contenidos en el censo electoral, con la finalidad del envío de la propaganda electoral y limitado al periodo de la campaña electoral. Una vez terminada la campaña, sólo podían hacerles llegar mensajes si contaban con el consentimiento expreso de los mismos, aunque en ningún caso solicitando el voto.

La LOREG no establecía pues referencia alguna a la utilización de medios tecnológicos para el envío de la propaganda electoral ni a la utilización del correo electrónico o telefonía móvil. Además, recordamos aquí, el censo no recoge el dato del correo electrónico, por lo que el envío a una dirección de correo electrónico requería en todo caso el consentimiento del elector que lo hubiera facilitado. ${ }^{49}$ No obstante, a pesar de lo dicho, fue la Junta Electoral Central (en adelante,

43 Sobre cómo las emociones podían ser transmitidas a través de Internet, modificando comportamientos, vid. Olier, E., «Algoritmos. El poder del control social», Telos, nº 110, pp. 60-67 (p. 63).

44 García SANZ, R.M., «Tratamiento de datos...», op. cit., p. 137.

45 Dictamen 3/2018 SEPD.

46 Oler, E., «Algoritmos.... », op. cit., p. 65.

47 García Mahamut, R., «Partidos políticos y... », op. cit., pp. 320-321.

48 García Mahamut, R., «Partidos políticos y... », op. cit., p. 312. Entre otros, vid. arts. 31-39, 41 (41.5), 53 y 58.bis) LOREG.

49 Además, deberíamos tener en cuenta que, en principio, sin regulación alguna por parte de la LOREG hasta la aprobación de la LOPDGDD, el envío de comunicaciones electrónicas podía ser considerado 
JEC), la que vino a colmar la laguna jurídica existente hasta la aprobación de la LOPDGDD y su modificación de la LOREG. Así, la JEC, en su Acuerdo de 3 de junio de 1991, interpretó que el envío de propaganda electoral a través de Intenet no era un acto prohibido por la normativa electoral,${ }^{50}$ lo que años más tarde vino a plasmar en sus Instrucciones de 2007 y $2011 .^{51}$

Por lo tanto, hasta la modificación de la LOREG por la LOPDGDD, y conforme a los pronunciamientos de la AEPD y de la JEC, el envio de propaganda electoral vía on line o a teléfonos móviles, cuando se enmarcara dentro de la campaña electoral, con los datos entregados por los propios electores (ya que ni correo electrónico ni número de teléfono móvil se recogen en el censo), y siempre y cuando se respetaran los principios del tratamiento de datos personales y las medidas de seguridad pertinentes, era totalmente posible. Más allá de la campaña electoral, el envío de propaganda electoral requeriría contar nuevamente con el consentimiento expreso de los electores y cumplir con el resto de exigencias en materia de protección de datos. Aunque el tema no estaba del todo claro.

Con la aprobación de la LOPDGDD y de la inclusión del art. 58.bis) LOREG se dió paso a la posibilidad de que los partidos políticos «recopilaran» las opiniones políticas de los ciudadanos en el marco de sus actividades electorales (posibilidad que ha sido declarada inconstitucional por la STC 76/2019); y de que los partidos políticos pudieran utilizar «los datos personales obtenidos en páginas web y otras fuentes de acceso público para la realización de actividades políticas durante el periodo electoral», ${ }^{52}$ entre las que se incluye «el envío de propaganda electoral por medios electrónicos o sistemas de mensajería y la contratación de propaganda electoral en redes sociales o medios equivalentes». ${ }^{53}$ Esta redacción deja en el aire muchas incógnitas que afectan no sólo a la propaganda electoral y a su financiación, ${ }^{54}$ pues el RGPD sigue permitiendo la «recopilación» de las opiniones políticas en su Considerando 56.

spam y el spam comercial está probido conforme al art. 21 LSSI salvo si cuenta con el consentimiento del titular de los datos.

50 Como recuerda García Mahamut, R., «Partidos políticos y... », op. cit., p. 320.

51 Vid. Instrucción 4/2007, de 12 de abril, de la Junta Electoral Central, sobre la utilización de las nuevas tecnologías de la información y de la comunicación electrónicas como instrumento de propaganda electoral; y la Instrucción 3/2011, de 24 de marzo, de la Junta Electoral Central, sobre interpretación de la prohibición de realización de campaña electoral incluida en el artículo 53 de la Ley Orgánica del Régimen Electoral General.

52 Art. 58.bis).2 LOREG.

53 Art. 58.bis).3 LOREG, que niega la consideración de actividad o comunicación comercial a esta propaganda electoral.

54 Informe de la Comisión de Venecia sobre Tecnologías Digitales y Elecciones, 2019, ha manifestado que mientras las sociedades no encuentren nuevas formas de financiar Internet, la imposición de límites excesivos a la mercantilización de la información personal podría restringir derechos políticos fundamentales como la libertad de expresión y la libertad de organización de la acción política, afirmando que «La paradoja es que las mismas tecnologías que han mejorado las posibilidades de expresión, son las que limitan dichas posibilidades» (Apdos. 36-37 y 133). 
La STC 76/2019 pretende dar respuesta al uso de la tecnología por los partidos políticos centrando su argumentación en el necesario respeto al contenido esencial del derecho a la protección de datos personales, ${ }^{55}$ pero si bien se pronuncia de la forma esperada, pues la redacción del precepto impugnado no daba lugar a otra conclusión, deja en el aire muchas otras cuestiones que la LOREG no soluciona y para lo que tendremos que acudir al RGPD y la AEPD. La cuestión no es tanto el envío de propaganda electoral vía on line - aspecto en el que se centraron la mayor parte de las quejas ciudadanas—, sino la manipulación que el utilizar nuestras opiniones políticas puede provocar en nuestro sistema democrático.

\section{ANTECEDENTES DE UNA INCONSTITUCIONALIDAD ANUNCIADA}

La reforma de la LOREG con el fin de regular el uso de las nuevas tecnologías, a pesar de haber sido una cuestión reclamada incluso por la propia Junta Electoral Central, ${ }^{56}$ no se produjo hasta la aprobación de la LOPDGDD.

No obstante, como ha quedado dicho, la interpretación de cómo proceder ante el tratamiento de las nuevas tecnologías en los procesos electorales por parte de los partidos políticos lo llevé a cabo la JEC con sus Instrucciones. Con la Instrucción 4/2017 se limitó a señalar que las limitaciones contenidas en la legislación electoral en materia de campaña electoral, o en un referéndum, debían ser aplicables a los sistemas de información y de comunicación electrónicos que se encontrasen directa o indirectamente bajo la dependencia de los partidos políticos. Y con la Instrucción 3/2011, por un lado, prohibía a las formaciones políticas y las candidaturas «contratar directamente ni a través de tercero, espacios, soportes o sitios para la difusión de publicidad o propaganda electoral....en formatos publicitarios en Internet («banners») ... o en otros soportes en medios digitales»; y, por otro lado, permitía, siempre que no se solicitara el voto, la realización de toda una serie de actividades, entre las que podemos citar el envío de correos electrónicos o de mensajes sms, o la distribución de contenidos por radiofrecuencia (bluetooth) para dar a conocer a los candidatos o el programa electoral, siempre que no implicara la contratación de un tercero para su realización. ${ }^{57}$

En pleno siglo XXI nos enfrentábamos pues a la omisión de las referencias a la normativa de protección de datos o al respeto a la privacidad o a la protección

55 Para el SEPD, casi quince años después de que las Autoridades de Protección de Datos y Privacidad, en su $27^{a}$ reunión en Suiza, exigieran un mayor rigor en el cumplimiento de la normativa de protección de datos, «puede que ahora sea el momento de renovar esta llamada» (Vid. Dictamen 3/2018 SEPD).

56 García Mahamut, R., «Partidos políticos y... », op. cit., p. 322, quien recuerda que la reforma de la LOREG de 2011 no incluyó, a pesar de haber sido sugerido por la propia JEC, el contenido de la citada Instrucción 4/2007.

57 García Mahamut, R., «Partidos políticos y... », op. cit., p. 323. 
de datos personales en las campañas electorales digitalizadas. Y la decisión de regularlo se produjo vía aprobación LOPDGDD. La cuestión no empezaba de la mejor manera.

De esta forma, la LOPDGDD introdujo no sólo la posibilidad de que los electores pudieran oponerse a que sus datos fueran entregados a los representantes de las candidaturas en la copia que reciben del censo electoral para realizar envíos postales de propaganda electoral (art. 39.3 LOREG), sino que introdujo la regulación de la «utilización de medios tecnológicos y datos personales en las actividades electorales» (art. 58.bis) LOREG). Pero incluso antes de que se publicara la norma, el revuelo que se levantó al respecto puso en entredicho su constitucionalidad.

Por ello, días antes de salir a la luz el art. 58.bis) LOREG, consciente de la preocupación ciudadana generada, el 21 de noviembre de 2018, la AEPD emitió una Nota de prensa con el fin de explicar a los ciudadanos que el controvertido artículo de la LOREG no iba a permitir elaborar perfiles basados en opiniones políticas ni el envío de información personalizada basada en perfiles ideológicos o políticos. ${ }^{58}$ Asimismo, con el fin de completar la deficiente redacción del citado artículo de la LOREG, la AEPD emitió diligentemente, el 19 de diciembre de 2018, su Informe jurídico 210070/2018, como antesala de la Circular que aprobaría meses más tarde, la Circular 1/2019, de 11 de marzo. Ambos documentos detallan, entre otros aspectos, el carácter excepcional de la posibilidad atribuida a los partidos políticos; la necesidad de contar con una finalidad clara y determinada que legitime el tratamiento; la necesidad de determinar los sujetos que pueden realizar los tratamientos; y la necesidad de concretar los datos a ser tratados, así como los tratamientos y el momento en el que pueden producirse ${ }^{59}$.

Pero esto no fue suficiente para frenar la preocupación por las posibilidades que permitía el texto legal vigente y así, el Defensor del Pueblo, haciéndose eco de las solicitudes instándole a interponer un recurso de inconstitucionalidad contra el art. 58.bis).1 LOREG $^{60}$, entendiendo que existían requisitos objetivos que

58 AEPD, Nota de prensa de 21 de noviembre de 2018, «Criterio de la Agencia Española de Protección de Datos sobre cuestiones electorales en el proyecto de nueva LOPD». A juicio de la Agencia: «El Proyecto sólo permite, conforme al Considerando 56 del Reglamento General de Protección de Datos, la recopilación por parte de los partidos políticos de datos personales relativos a opiniones políticas para obtener información que les permita pulsar las inquietudes de los ciudadanos con el fin de poder darles respuesta en sus propuestas electorales. Esta interpretación se fundamenta en la supresión del término „tratamiento « recogido en la enmienda 331 inicialmente presentada en el Congreso. Este criterio se basa, asimismo, en la supresión del apartado 2 de dicha enmienda, que permitía la difusión de propaganda electoral basada en perfiles ideológicos con determinadas garantías»".

59 Un rápido análisis de ambos textos, con una opinión crítica de los mismos, lo encontramos en López Martínez, J., «Partidos políticos y... », op. cit. .

60 Tras la aprobación de la LOPDGDD y la consiguiente modificación de la LOREG, fueron varios Abogados especialistas en protección de datos y cinco Asociaciones (Asociación de Internautas (AI), Asociación de Usuarios de Internet (AUI), Plataforma en Defensa de la Libertad de Información (PDLI), Asociación de Expertos Nacionales de la Abogacía Digital (ENATIC), e ISACA Capítulo Madrid), los que se dirigieron al Defensor del Pueblo solicitándole su ayuda y actuación. 
demostraban dicha tacha de inconstitucionalidad, interpuso el correspondiente recurso ante el Tribunal Constitucional en marzo de 2019.

\section{LA STC 76/2019: LA LESIÓN DEL CONTENIDO ESENCIAL DEL DERECHO A LA PROTECCIÓN DE DATOS PERSONALES}

El Tribunal Constitucional se pronuncia, en pleno y por unanimidad de sus miembros, sobre el asunto mediante Sentencia 76/2019, de 29 de mayo, declarando la inconstitucionalidd del art. 58.bis). 1 LOREG. ${ }^{61}$

Son varios los argumentos esgrimidos por el Defensor del Pueblo contra el precepto impugnado y que se concretan, básicamente, en tres aspectos: en primer lugar, que el mismo no reflejaba una finalidad determinada que justificara el tratamiento realizado; en segundo lugar, que el artículo no establecía ni las condiciones, requisitos o restricciones que permitían el tratamiento de los datos; y, en tercer lugar, que el texto enjuiciado no establecía las garantías adecuadas para proteger los derechos derivados del tratamiento realizado. Todas estas cuestiones generaban, a juicio del Defensor del Pueblo, por un lado, una evidente inseguridad jurídica, contraria a lo dispuesto en el art. 9.3 de nuestro texto constitucional, y contraria al propio contenido esencial del derecho a la protección de datos, lesionando el art. 18.4 CE en conexión con el art. 53.1 CE. Y, por otro lado, dado que hablamos de opiniones políticas y su manifestación, se lesionaba tanto la libertad ideológica garantizada por el art. $16 \mathrm{CE}$, como el derecho de participación política garantizado por el art. 23.1 CE.

Por su parte, el Abogado del Estado puso de manifiesto que, a su juicio, el precepto impugnado no adolecía de inconstitucionalidad alguna, y centró su alegato en la no vulneración del principio de seguridad jurídica argumentando que el art. 58.bis). 1 LOREG respetaba el contenido esencial del derecho a la protección de datos y ofrecía las garantías adecuadas, haciendo innecesario analizar el resto de argumentos alegados por el Defensor del Pueblo. Para el Abogado del Estado, tanto el RGPD como la LOPDGDD recogen las garantías adecuadas a las que alude la LOREG para permitir a los partidos tratar las opiniones políticas de los ciudadanos; garantías, que a su juicio (mor de una interpretación sistemática),

61 Al respecto sobre esta Sentencia, vid. Pascua Mateo, F.A., «Un nuevo capítulo en la tutela del derecho a la protección de datos personales: los datos de contenido político. Comentario a la Sentencia del Tribunal Constitucional 76/2019, de 29 de mayo, en el recurso de inconstitucionalidad núm. 1405-2019 (B.O.E. núm. 151, 25 de junio de 2019)», Revista de las Cortes Generales, n 106, 2019, pp. 549-558. Este autor, como muchos comentarios que surgieron respecto de la sentencia destacaron la rapidez del pronunciamiento constitucional: «Es, seguramente, la sentencia en un proceso de inconstitucionalidad más rápida que se haya dictado» (p. 553). Vid., también, Arenas RAmiro, M., «La inconstitucionalidad del artículo 58.bis). 1 LOREG y la prohibición de recopilar opiniones políticas de los ciudadanos: a propósito de la STC 76/2019», La Ley Privacidad, n 2, Diario La Ley (on line), 2019. 
deben completarse con la interpretación realizada de dichas normas por la AEPD en su Informe y en la Circular 1/2019. ${ }^{62}$

El TC comienza identificando en sus Fundamentos Jurídicos el núcleo de la controversia planteada y concluye que la impugnación central no es otra que la relacionada con la lesión del contenido esencial del derecho a la protección de datos personales, reconocido por el art. 18.4 CE, en conexión con el art. 53.1 CE y la exigencia de reserva de ley. Para el TC, de dicha impugnación cuelgan el resto de impugnaciones realizadas como complementarias. Por ello, nuestro alto Tribunal analiza primero el contenido esencial del derecho a la protección de datos bajo la premisa de que el mismo puede verse limitado — como cualquier otro derecho fundamental—, para pasar a analizar después dicha limitación, ${ }^{63}$ interpretada de forma restrictiva, so pena de generar indeterminación e incertidumbre, inseguridad jurídica, dejando que la aplicación de la norma y la determinación de sus límites quede a «la voluntad de quien ha de aplicarla» ${ }^{64}$ y permitiendo una más fácil intromisión en el contenido esencial del derecho, desnaturalizándolo. ${ }^{65}$

\section{Fin legítimo}

Todo tratamiento de datos personales debe tener una base que lo legitime. Tanto el RGPD como la LOPDGDD señalan cuáles son las bases de legitimación de los tratamientos de datos personales, así como las de los datos especialmente protegidos, como ya hemos analizado, ${ }^{66}$ a la vez que indican que la finalidad perseguida debe ser determinada y legítima, como también establecen los principios del tratamiento de datos personales. ${ }^{67}$

En el caso de los partidos políticos, esto implica que dicha finalidad debe concretarse y responder a la pregunta de para qué van a recopilar datos los

62 Según Ricard Martínez, el problema del art. 58.bis) LOREG «plantea un único problema específico: la interpretación sistemática de la redacción del párrafo primero». Para este autor, «si realizamos una lectura del precepto integrando sus disposiciones con los deberes y procedimientos del Reglamento General de Protección de Datos debería resultar un modelo en el que los partidos puedan realizar campañas propias del S. XXI y el ciudadano disponga de herramientas para oponerse a los tratamientos». Por el contrario, para BORJA ADSUARA «la interpretación sistemática no puede corregir la interpretación del precepto «según el sentido propio de sus palabras», que es el primer criterio interpretativo de las normas (art. 3.1 del Código Civil), que contradice frontalmente las previsiones del RGPD». Vid. Adsuara Varela, B. / Martínez Martínez, R., «Debate sobre el...», op. cit..

63 STC 76/2019, FJ 50.d).

64 Así ya lo dijo la STC 292/2000, FJ $15^{\circ}$.

65 González Fuster, G., «Curtaling a right in flux: restrictions of the right to personal data protection», en Rallo Lombarte, A. / García Mahamut, R. (Eds.), Hacia un nuevo Derecho europeo de protección de datos, Tirant lo Blanch, Valencia, 2015, pp. 513-537 (p. 532).

66 Art. 6 RGPD y art. 8 LOPDGDD, que en el caso del interés público exige, además que se deberá derivar de «una competencia atribuida por una norma con rango de ley». Y art. 9 RGPD y art. 9 LOPDGDD.

67 Art. 5.1.b) RGPD, que se refiere concretamente al principio de «limitación de la finalidad». 
partidos políticos. ${ }^{68}$ Conocer la finalidad es esencial, pues es para lo que se consiente el tratamiento, ${ }^{69}$ y evita el riesgo de discrecionalidad y arbitrariedad. ${ }^{70}$ Por ello, además, teniendo una finalidad determinada si las plataformas o servidores on line recogen datos con fines comerciales, los mismos no podrán ser tratados posteriormente en el contexto electoral. «Salvo que las fundaciones y los partidos políticos actúen con diligencia debida y comprueben que los datos han sido obtenidos legalmente, no podrán utilizar este tipo de datos obtenidos de un tercero». ${ }^{71}$

En la STC 76/2019, el Tribunal Constitucional considera que el art. 58.bis).1 LOREG no especifica la finalidad que legitima que los partidos políticos puedan recabar las opiniones políticas de los ciudadanos. Para el TC, el argumento de que el tratamiento es necesario para un «interés púbico» — como dice la LOREGy, con ello, para el correcto funcionamiento de un Estado democrático y que los partidos políticos puedan conocer así la opinión de los electores exclusivamente en los procesos electorales — como señala el Abogado del Estado_-, no es lo suficientemente específico, sino que es una referencia vaga ${ }^{72}$, y puede acabar en un «razonamiento circular» ${ }^{73}$.

La limitación de un derecho fundamental no puede basarse en la mera referencia genérica a un «interés público», pues evita cualquier tipo de enjuiciamiento concreto o el análisis de su proporcionalidad ${ }^{74}$, siendo pues contraria al respeto del contenido esencial del derecho en cuestión. ${ }^{75}$ Asimsimo, la limitación del concepto de interés público se hace esencial en este ámbito con el fin de hacer frente a los abusos y manipulaciones que se producen en los entornos digitales, y a su concreción deberían encaminarse las Autoridades de Protección de Datos. ${ }^{76}$

68 Según el Informe jurídico 210070/2018 AEPD: «El Informe se limita a exigir que la finalidad, a determinar por los propios partidos políticos y demás legitimados, guarden relación con relación con su actividad electoral relativa a la propaganda y actos de campaña electoral, «dentro de la finalidad genérica de captación de sufragios a la que se refiere el artículo 50.4 LOREG»».

69 Sobre esta cuestión, vid. SAN de 22 de febrero de 2019, sobre la sanción impuesta al Ayuntamiento de Madrid por la utilización de datos de carácter personal, direcciones de correo electrónico de los vecinos, para finalidades distintas de las que figuraban en el registro para el que se obtuvieron, en relación con Línea Madrid.

70 García SAnZ, R.M., «Tratamiento de datos...», op. cit., p. 132. Para esta autora, con tanta indeterminación, imprecisión y conceptos laxos y abiertos, «lejos de ofrecer seguridad, el Reglamento presenta una mayor incertidumbre, y podría dar, irónicamente, cobertura legal incluso a prácticas poco respetuosas, en virtud de sus conceptos jurídicos indeterminados y vagos» (p. 133).

71 Documento de Orientación de la Comisión Europea sobre Elecciones libres y limpias, 2018.

72 A este tipo de expresiones, limitativas del derecho, se opuso la STC 292/2000, FFJJ $16^{\circ}$ y $17^{\circ}$.

73 STC $76 / 2019$, FJ $7^{\circ}$.a)

74 STC $76 / 2019$, FJ $7^{\circ}$.a)

75 Además, el Informe jurídico 210070/2018 AEPD informa de que «al tratarse de una excepción al tratamiento de las categorías especiales de datos personales debe ser objeto de interpretación restrictiva». Sobre las limitaciones, vid. GARcía SANZ, R.M., «Tratamiento de datos...», op. cit., p. 154; con referencia a Rubinstein, I.S. / Nojeim, G.T. / LeE, R.D., «Systematic government access to personal data: a comparative análisis», International Data Privacy Law, 4 (2), 2014, pp. 96-119 (p. 114).

76 Entre las recomendaciones del SEPD en su Dictamen 3/2018 SEPD. 


\section{Criterios determinados}

Es esencial que todo tratamiento de datos tenga una finalidad determinada, pero más allá de la finalidad, todos los aspectos que rodean un tratamiento de datos personales, especialmente cuando nos referimos a categorías especiales de datos, deben estar determinados, desde quién es el responsable del tratamiento hasta las circunstancias en las que los mismos pueden producirse. El principio de transparencia de los datos así lo exige. ${ }^{77}$ Asimismo, recordamos aquí, como hace nuestro Tribunal Constitucional, que estamos hablando de un supuesto sumamente excepcional ya que se levanta la prohibición genérica de tratar datos personales referidos, además, a datos especialmente protegidos. Ello provoca que la injerencia en el derecho a la protección de datos deba encontrarse debidamente legitimada y detallada. ${ }^{78}$

Por ello, junto a la necesidad de concretar el interés público específico que legitime el tratamiento de las opiniones políticas de los ciudadanos por parte de los partidos políticos, la STC 76/2019 analiza la segunda tacha de inconstitucionalidad del art. 58.bis).1 LOREG basada en que dicho precepto no concreta ni el alcance ni el contenido de los tratamientos de datos que pueden producirse. ${ }^{79}$

En primer lugar, los datos personales que pueden ser tratados, así como los concretos tratamientos que podrán llevarse a cabo con los mismos deben ser especificados. Estamos hablando de opiniones políticas. A ellas se refiere la LOREG. Pero en la STC 76/2019 el TC pone de manifiesto que el artículo impugnado tampoco concreta el alcance y contenido de los tratamientos que se autoriza, ni respecto de los datos tratados, ni respecto de las operaciones efectuadas con los mismos, ${ }^{80}$ pues se refiere genéricamente a una recopilación, pero nada se dice de si en los tratamientos permitidos las opiniones políticas se podrán comunicar o transferir a terceros. ${ }^{81}$

77 Art. 5.1.a) RGPD y art. 13 LOPDGDD

78 Así lo puso ya de manifiesto la STC 292/2000 en su FJ $9^{\circ}$ donde, recordando la doctrina del TEDH, señaló que las limitaciones a este derecho deben estar previstas legalmente y ser las indispensables en una sociedad democrática, lo que implica que la ley que establezca esos límites sea accesible al individuo concernido por ella, que resulten previsibles las consecuencias que para él pueda tener su aplicación y que los límites respondan a una necesidad social imperiosa y sean adecuados y proporcionados para el logro de su propósito (entre muchas otras, STEDH de 26 de marzo de 1987, caso Leander).

79 Para el TC la falta de determinación de estas condiciones está íntimamente ligada con la imposibilidad de identificar la finalidad realmente perseguida y a la inversa (STC 76/2019, FJ $7^{\circ}$.b)).

80 Del Informe jurídico 210070/2018 AEPD destaca la confirmación de que el envío de propaganda electoral por medios electrónicos o sistemas de mensajería y la contratación de propaganda electoral en redes sociales o medios equivalentes, no tiene la consideración de actividad o comunicación comercial, por lo que no le será de aplicación el art. 21 LSSI. Para López MARTínez, «no concibo que la propaganda electoral por vía mail no encaje en el concepto de comunicaciones comerciales en el contexto que el mismo tiene en la LSSI 34/2002» (López Martínez, J., «Partidos políticos y... », op. cit.).

81 En la Circular 1/2019 AEPD se señala que hay que decidir y determinar las actividades de tratamiento, bastando con que sean «proporcionales al objetivo perseguido consistente en garantizar el adecuado funcionamiento de un sistema democrático», evitando «tratamientos no proporcionales como el microtargeting» o «los que tengan por finalidad forzar o desviar la voluntad de los electores», confirmando 
Si nos centramos en el entorno on line, resulta complejo identificar lo que es una opinión política y por lo tanto, lo que es un dato personal que puede o no ser recopilado, provocando que se puedan recoger o tratar más datos de los necesarios o incluso datos que no sean adecuados para la finalidad perseguida. Por ello se produce una evidente violación de los principios de tratamieto de datos personales. ${ }^{82}$.

Es la Circular 1/2019 AEPD la que concreta que solo podrán ser objeto de recopilación las opiniones políticas de las personas libremente expresadas por éstas en el ejercicio de sus derechos a la libertad ideológica y a la libertad de expresión, pero que, en ningún caso, podrán ser objeto de tratamiento otro tipo de datos personales a partir de los que, aplicando tecnologías como las de tratamiento masivo de datos o las de inteligencia artificial, se puede llegar a inferir la ideología política de una persona. ${ }^{83}$

Asimismo, las opiniones políticas utilizadas, que ya no podrán ser recopiladas, serán aquéllas que se puedan obtener de «las páginas web y aquellas otras fuentes que sean de acceso público». ${ }^{84}$ Sobre esta cuestión el TC en la Sentencia 76/2019 señaló que tampoco se concretaba si la recopilación se haría sólo de las páginas web y otras fuentes accesibles al público, o de otras fuentes. ${ }^{85}$ En este sentidio, de nuevo la Circular concreta que el tratamiento de otros datos u obtenidos de otras fuentes, o de aquéllas restringidas a un círculo determinado de personas, deberán tener una base legítima y estar entre las excepciones a la prohibición de tratar datos especialmente protegidos, para poder ser tratados. Recordamos aquí que el RGPD permiter tratar datos que el titular haya hecho manifiestamente públicos.

Cuando hablamos de un entorno on line la dificultad es delimitar el territorio o el espacio y distinguir de una forma clara, sin género de dudas, el espacio público del privado, pero más allá de que técnicamente se pueda deterctar quién manda un mensaje o la propaganda electoral, se podrían concretar los espacios virtuales de los que se pueden recoger o utilizar datos, como redes sociales, blogs o webs y, así, delimitar qué fuentes son accesibles para los partidos, concretando los datos o categorías de datos a los que se puede acceder, cumpliendo, por lo tanto, con el principio de minimización de los datos. ${ }^{86}$

que al márgen de esto, los partidos políticos sí podrán enviarnos propaganda elctoral por medios electrónicos, salvo expresa oposición nuestra.

82 En concreto se lesiona el principio de minimización de los datos, reconocido en el art. 5.1.c) RGPD. Al respecto, vid. GARcía SANZ, R.M., «Tratamiento de datos...», op. cit., p. 152.

83 Art. 5.1 y 2 Circular 1/2019 AEPD.

84 Art. 5.3 Circular 1/2019 AEPD.

85 Respecto a la obtención de «páginas web y otras fuentes de acceso público» nos decía el Informe jurídico 210070/2018 AEPD que, aunque en la nueva normativa ha desaparecido la referencia a las «fuentes accesibles al público», podía seguir utilizándose, adaptándola al contexto actual, la definición que se contenía en el artículo 3.j) de la derogada Ley Orgánica 15/1999 (LOPD): «aquellos ficheros cuya consulta puede ser realizada, por cualquier persona, no impedida por una norma limitativa o sin más exigencia que, en su caso, el abono de una contraprestación», lo que excluiría otro tipo de fuentes en las que el acceso está restringido a un círculo determinado, ya sea como «amigo» u otro concepto similar.

86 García SAnz, R.M., «Tratamiento de datos...», op. cit., pp. 152-153. 
Dado que, conforme permite la LOREG, los partidos políticos podrán enviar propaganda electoral vía on line sin consentimiento de los electores, los datos empleados para dichos envíos podrán ser, como señala la AEPD en su Circular 1/2019, desde los números de teléfono, el correo electrónico u otros similares, pero deberán pertenecer a "personas que puedan ejercer su derecho al voto en el ámbito de la circunscripción que se corresponda con el proceso electoral al que se presenten». ${ }^{87}$ Por otro lado, los envíos se podrán realizar no sólo por los medios tradicionales de los que habla la LOREG, sino como ahora también recoge, «por medios electrónicos o sistemas de mensajería y la contratación de propaganda electoral en redes sociales o medios equivalentes no tendrán la consideración de actividad o comunicación comercial». .8

Sobre los tratamientos que se podrán realizar de las opiniones políticas, si bien la recopilación ha quedado anulada por el Tribunal Constitucional en la STC 76/2019, la LOREG sigue permitiendo en el resto de apartados del art. 58.bis) LOREG tratamientos como la utilización para la realización de actividades políticas durante el periodo electoral. No obstante, es la Circular 1/2019 la que señala que, en ningún caso, dentro de ese tratamiento se encuentra la comunicación o cesión de las opiniones políticas a terceros ${ }^{89}$ Más aún, la citada Circular señala que el responsable del tratamiento debe determinar las actividades que va a realizar y que, en todo caso, las mismas «deberán ser proporcionales al objetivo perseguido consistente en garantizar el adecuado funcionamiento de un sistema democrático, sin que sean admisibles tratamientos no proporcionales como el microtargeting ni los que tengan por finalidad forzar o desviar la voluntad de los electores». ${ }^{90}$

En este sentido, como puede verse, la elaboración de perfiles personalizados está prohibido. Pero si se pretendieran realizar perfiles que no fueran dirigidos a una persona en concreto o individualizado o por categorías muy específicas (microtargeting), sino generales o por categorías genéricas, como permite el RGPD, la propia Circular señala que «se deberá ser especialmente riguroso con el nivel de detalle y la exhaustividad del mismo». Según la Circular, en este sentido, «sólo se puedan deducir patrones de conducta generales de la población de forma agregada, pero no de titulares de datos personales concretos»..$^{91}$

En segundo lugar, sobre quién puede recoger datos relacionados con las opiniones políticas, para nuestro máxime Tribunal, el art. 58.bis).1 LOREG no concreta si la recogida de las opiniones políticas la llevarán a cabo sólo los partidos políticos o podrán hacerlo igualmente federaciones, coaliciones y agrupaciones de

87 Art. 11.1 y 2 Circular 1/2019 AEPD

88 Art. 58.bis).3 LOREG.

89 Art. 2.4 Circular 1/2019 AEPD.

90 Art. 6.1 Circular 1/2019 AEPD.

91 Art. 6.2 Circular 1/2019 AEPD. 
electores, o incluso, si se podrían encargar a un tercero. ${ }^{92}$ En este caso, fue la Circular 1/2019 AEPD la que se encargó de concretar este extremo, limitando el ámbito del tratamiento a la circunscripción que se correspondiera con el proceso electoral al que se presentaran en concreto "partidos políticos, federaciones, coaliciones y agrupaciones de electores que presenten las correspondientes candidaturas y resulten proclamadas conforme a los artículos 43 y siguientes de la LOREG». ${ }^{93}$ Asimismo, la Circular vino a señalar también que dicho tratamiento podría encargarse a otro sujeto que actuara como encargado del tratamiento, firmando el correspondiente acuerdo con los responsables del tratamiento, pero que en ningún caso dicho tratamiento podría ser comunicado o transferido a un tercero. ${ }^{94}$

Será en el terreno de la contratación de espacios electorales a terceros donde se produzcan más conflictos a la hora de determinar quién puede recoger y tratar las opiniones políticas de los ciudadanos. ${ }^{95}$ Es importante analizar cada caso concreto y determinar quién ostenta el papel de responsable y quién el papel de encargado, si existiera, pues en el contexto electoral, las plataformas y empresas de análisis de datos pueden ser (conjuntamente) responsables o encargados del tratamiento, dependiendo del grado de control y de la definición de los fines y medios que tengan en cada proceso. ${ }^{96}$

En tercer lugar, a la pregunta de cuándo se puede producir la recogida de las opiniones políticas o cuándo se podrán utilizar estas opiniones políticas, el artículo enjuiciado en la STC 76/2019 en primer lugar se limitaba a señalar para la recopilación un impreciso marco de «actividades electorales»; y, para su utilización se vincula a la «realización de actividades políticas durante el periodo electoral». Para nuestro TC el marco de las actividades políticas para la recogida es un marco demasiado amplio y genérico si tenemos en cuenta, no sólo que «los procesos electorales son relativamente frecuentes en nuestro sistema político» ${ }^{97}$, sino que dichas actividades pueden realizarse tanto durante la campaña electoral como en cualquier otro momento. ${ }^{98}$ Se hace necesario concretar esa finalidad electoral pues en caso contrario el volumen de información personal que puede llegar a utilizarse puede ser ingente, en contra del principio de minimización de los datos.

92 En el Informe jurídico 210070/2018 AEPD se hace una interpretación «amplia» a este respecto, lo que llama la atención a López Martínez (López MARTínez, J., «Partidos políticos y... », op. cit. .

93 Art. 2.1 y 2 Circular 1/2019 AEPD.

94 Art. 2.3 y 4 Circular 1/2019 AEPD.

95 Martínez Martínez, R. «Partidos, algoritmos y...», op. cit., p. 135.

96 Documento de Orientación de la Comisión Europea sobre Elecciones libres y limpias, 2018.

97 STC 76/2019, FJ $7^{\circ}$.b).

98 A la pregunta de cuándo podrán tratarse datos, la Circular 1/2019 AEPD confirma que «solo» durante el periodo electoral (según la Junta Electoral Central, se entiende por periodo electoral el comprendido entre la fecha de publicación de la convocatoria de las elecciones en el Boletín oficial correspondiente y el día mismo de la votación), y únicamente para las actividades de propaganda y actos de campaña electoral reguladas en los arts. 53 a 58 bis de la LOREG». 
Nada justifica, salvo razones de amenaza democrática, una monitorización permanente, una recopilación o uso permanente de los datos personales de los electores. ${ }^{99}$ Fue la Circular 1/2019 AEPD la que limitó la recopilación y utilización de los datos al periodo electoral y respecto de las actividades de propaganda y actos de campaña electoral reguladas en la sección 5. ${ }^{a}$ del capítulo VI del título I de la LOREG. ${ }^{100} \mathrm{Si}$ bien es evidente que fuera de la campaña o periodo electoral el peligro de manipulación de la información se incrementa, la utilización de las opiniones políticas podría estar justificada, como situación excepcional, en campaña electoral, como se hace en el caso de los medios de comunicación tradicionales. ${ }^{101}$

Esto significa que, conforme a la LOREG, los datos personales podrán ser tratados sólo para los fines electorales contemplados en dicha norma, lo que incluye tanto el control de las elecciones en las propias mesas electorales por parte de los interventores y, fuera de ello, para hacer llegar la propaganda y la publicidad electoral al domicilio del elector en período de campaña electoral. Y, finalizada la campaña electoral, ya fuera del período electoral, los partidos no pueden utilizar los datos personales contenidos en copias del censo electoral para ningún fin sin obtener previamente el consentimiento de las personas afectadas para usar y tratar sus datos con fines de comunicación política. Si bien la cuestión se plantea en el correcto juego democrático y en comprobar que el tratamiento de datos se haya producido en el marco de los quince días establecidos para la campaña electoral por la LOREG, se debería prestar más atención al uso masivo que se hace de los datos personales más allá de dicha campaña electoral.

Asimismo, en relación con esa actividad de propaganda que se puede realizar en periodo electoral, debemos señalar que la LOREG recoge, a diferencia de los países de nuestro entorno, como en el Reino Unido, que dicha comunicación no tiene el carácter de publicidad comercial, por lo que escapa a las reglas de las comunicaciones electrónicas no solicitadas o comunicaciones comerciales y, por lo tanto, a la LSSI y a las exigencias del consentimiento. En relación con el envío de propaganda electoral por medios electrónicos o sistemas de mensajería y contratación de propaganda electoral en redes sociales o medios equivalentes, la Circular 1/2019 AEPD dispone que los datos personales utilizados para el envío de la citada propaganda electoral deberán haber sido obtenidos lícitamente y deberán identificarse como envío electoral y la identidad del remitente, ${ }^{102}$ actividades

99 García SANZ, R.M., «Tratamiento de datos...», op. cit., p. 151, quien señala que una monitorización permanente produciría un efecto disuasorio sobre la libertad de expresión o sobre el propio derecho de sufragio, vaciándolo de contenido.

100 Art. 4 Circular 1/2019 AEPD.

101 García Sanz, R.M., «Tratamiento de datos...», op. cit., p. 151; y Holgado González, M., «Publicidad e información sobre elecciones en los medios de comunicación durante la campaña electoral», Teoría y Realidad Constitucional, $\mathrm{n}^{\circ}$ 40, 2017, pp. 457-485.

102 Art. 11.2 Circular 1/2019 AEPD. 
divulgativas que deberán identificar «de modo destacado» su naturaleza electoral. ${ }^{103}$ Pero no necesitan el consentimiento de los electores.

Por último, el TC manifiesta que en el precepto impugnado tampoco se concretan las facultades de disposición y control de los datos cuya recopilación se autoriza, ni la entidad o sujeto que deberá darles respuesta. De nuevo, es la Circular 1/2019 AEPD la que señala que en los envíos de propaganda electoral a los electores se les deberá facilitar «un modo sencillo y gratuito el ejercicio de los derechos de acceso, rectificación, supresión, limitación del tratamiento y oposición, con especial atención en el caso de este último, conforme al apartado 5 del artículo 58.bis) LOREG. En caso de ejercicio del derecho de oposición, los datos personales dejarán de ser tratados para el envío de propaganda electoral mientras el afectado no preste su consentimiento expreso». ${ }^{104}$

Por todos estos motivos e imprecisiones, el TC concluye que la inseguridad jurídica generada a ciudadanos, partidos políticos y resto de operadores jurídicos - y contraria al art. 9.3 CE—, contradice la exigencia de respetar el contenido esencial del derecho y la obligación de que las normas que lo desarrollen cumplan con los requisitos propios de claridad, accesibilidad y previsibilidad, tal y como se deriva del art. 53.1 CE.

\section{Garantías adecuadas}

La tercera impugnación presentada por el Defensor del Pueblo gira en torno al análisis de la alegada ausencia de garantías adecuadas. El art. 58.bis).1 LOREG se limita a señalar que la recogida de las opiniones políticas se producirá «únicamente cuando se ofrezcan garantías adecuadas».

En relación con esta impugnación el TC confirma, en primer lugar, que el precepto impugnado no remite expresamente a ninguna otra norma y, por otro lado, que lo que se produce es una remisión implícita al RGPD y a la LOPDGDD, lo cual, a su juicio, es insuficiente respecto de las exigencias constitucionales del principio de reserva de $l e y^{105}$. Asimismo, el TC añade — sin restar importancia a los pronunciamientos de la AEPD, y al carácter vinculante de sus Circulares ${ }^{106}$, así como a la interpretación sistemática de nuestro ordenamiento ${ }^{107}$ — , que «las garantías adecuadas deben estar incorporadas a la propia

103 Art. 58.bis).4 LOREG.

104 Art. 11.3 Circular 1/2019 AEPD.

105 STC 76/2019, FJ $8^{\circ}$.c).

106 Art. 55 LOPDGDD. En el Dictamen 3/2018 SEPD, el SEPD puso de manifiesto que «Las directrices de las autoridades nacionales de protección de datos pueden ofrecer una interpretación autorizada adicional de las disposiciones de la legislación sobre protección de datos y privacidad».

107 Si bien el Abogado del Estado recurrió para su argumentación a la fundamentación del art. 58.bis) LOREG, recogida en la Enmienda parlamentaria que lo introdujo en el Proyecto de ley de la LOPDGDD, el TC señala que la Enmienda tiene, como los demás trabajos y debates parlamentarios, un importante elemento 
regulación legal del tratamiento, ya sea directamente o por remisión expresa y perfectamente delimitada a fuentes externas que posean el rango normativo adecuado» ${ }^{108}$.

En segundo lugar, como dice el TC, la inexistencia de unas garantías adecuadas deja vacío el contenido esencial del derecho, máxime cuando de lo que estamos hablando es de la ausencia de garantías ante el tratamiento de datos especialmente protegidos. El TC concluye, recordando que es jurisprudencia reiterada suya ${ }^{109}$, del TJUE y del $\mathrm{TEDH}^{110}$, que «las garantías adecuadas deben velar por que el tratamiento de datos se realice en condiciones que aseguren la transparencia, la supervisión y la tutela judicial efectiva, y deben procurar que los datos no se recojan de forma desproporcionada y no se utilicen para fines distintos de los que justificaron su obtención» ${ }^{111}$. No obstante, el TC señala también, en este punto, que el nivel y la naturaleza de las garantías adecuadas «no se pueden determinar de una vez para todas» y que deben, por un lado, ser revisadas y actualizadas; y, por otro lado, que las mismas deben cumplir con el principio de proporcionalidad, buscando las posibilidades de tratamiento menos intrusivas, lo que variará, por lo tanto, en función del tipo de los datos y de su naturaleza ${ }^{112}$. Toca pues determinar las garantías y aquí no podemos negar la importancia de la Circular 1/2019 de la Agencia.

\section{EL SIGUIENTE PASO: PRINCIPIOS Y GARANTÍAS ADECUADAS}

Declarada la inconstitucionalidd del art. 58.bis).1 LOREG y prohibida la recopilación de las opiniones políticas por parte de los partidos políticos, la cuestión surge ante el hecho de que en la práctica, el tratamiento de datos personales por partidos políticos se ha hecho, se hace y se hará, y que el RGPD sigue permitiendo dicha posibilidad. Y si bien es cierto que dicha posibilidad viene prevista en un Considerando y no en un artículo del Reglamento comunitario, dicha posibilidad sigue abierta. Asímismo, el envío de propaganda electoral durante la campaña electoral utilizando nuestros datos personales - los contenidos en el censo, así como los que se encuentren on line- está

hermenéutico, pero que su contenido y justificación «no pueden suplir o sanar las insuficiencias constitucionales de que adolezcan estas últimas (las normas)» (STC 76/2019, FJ 8.b)).

108 STC 76/2019, FJ $8^{\circ}$.

109 Por todos, STC 292/2000, FJ $10^{\circ}$; y SSTC 254/1993; y 143/1994, FJ $7^{\circ}$.

110 STJUE de 8 de abril de 2014, asunto Digital Rights Ireland Ltd., § 54; y SSTEDH, de 1 de julio de 2008, asunto Liberty y otros contra Reino Unido, $\$ \S 62$ y 63; de 4 de mayo de 2000, asunto Rotaru contra Rumanía, \$§ 57-59; y de 4 de diciembre de 2008, asunto Marper contra Reino Unido, § 99.

111 STC 76/2019, FJ 6 $\left.6^{\circ} . c\right)$. land Ltd.

112 STC 76/2019, FJ 6.c). Así, también, STJUE, de 8 de abril de 2014, asunto Digital Rights Ire- 
permitida y no requiere de nuestro consentimiento, al no ser la propaganda on line publicidad comercial.

La prohibición se ha concretado en la recopilación de las opiniones políticas sin las garantías adecuadas. Para que los partidos políticos pudieran «recopilar» nuestras opiniones políticas de la Red, dicha actividad debería producirse «en el marco de actividades electorales», por ser necesario para «el funcionamiento del sistema democrático»y por razones de interés público, pero «siempre que se ofrezcan garantías adecuadas». El siguiente paso lógico es pues concretar estas garantías adecuadas.

Como el SEPD ha reiterado, en los casos de datos especialmente protegidos, es fundamental reforzar su protección reforzando los principios de transparencia, limitación de la finalidad y minimización de los datos, así como concretando las salvaguardias contra la elaboración ilícita de perfiles y la adopción automatizada de decisiones. ${ }^{113}$ Además, teniendo en cuenta la transformación digital que vivimos, el legislador debería concretar los principios que hasta ahora venía aplicando a los medios de comunicación tradicionales al entorno on line, «con tanta o mayor minuciosidad». ${ }^{114}$

Ya en 2005 las Autoridades de Protección de Datos fijaron una serie de principios para garantizar el correcto uso de los datos personales durante las campañas electores, ${ }^{115}$ lo que la Circular 1/2019 de nuestra Autoridad de control ha concretado como «garantías adecuadas». ${ }^{116} \mathrm{Si}$ bien la Circular recoge una serie de medidas de protección para el caso de que sea necesario tratar datos personales sensibles por un interés público esencial, la lista elaborada no obedece a una lista cerrada, sino que los responsables del tratamiento, así como otros órganos en el ámbito de sus

113 Vid. Dictamen 3/2018 SEPD, donde el SEPD recordaba que las medidas concretas, así como la necesidad de que se recogieran normativamente, se plantearon en las propuestas que el mismo realizó al Proyecto del conocido como Reglamento e-Privacy (Al respecto, vid., disponible on line, el Dictamen 6/2017 SEPD, sobre la Propuesta de Reglamento sobre Privacidad y Comunicaciones Electrónicas (Reglamento e-Privacy): https://edps.europa.eu/sites/edp/files/publication/17-04-24_eprivacy_en.pdf, pp. 16-17.

114 García Sanz, R.M., «Tratamiento de datos...», op. cit., p. 147.

115 Se hablaba de reforzar el principio de minimización de los datos; de una recopilación legítima y justa, a la vez que informada; de la necesidd de que los datos tratados fueran precisos, pertinentes, no excesivos y actualizados en relación con los objetivos específicos para los que se recopilan, en especial, cuando la información está relacionada con la opinión política o social o las convicciones éticas del interesado; de cumplir con el principio de finalidad, especialmente en el caso de datos que hayan podido ser recopilados en el ejercicio de funciones institucionales y se quieran utilizar para la comunicación política recopilados; de la necesidad de cumplir con el principio de proporcionalidad, de forma pertinente al objetivo perseguido; de informar a los interesados, especificando la identidad del responsable y los flujos de datos que se esperan; de contar con el consentimiento, teniendo en cuenta la especialidad de los datos tratados; de respetar las normas relacionadas con la vía por la que se establecerá el contacto con los electores; de almacenar y proteger los datos que eviten su pérdida, alteración o uso indebido; de otorgar y garantizar los derechos de los interesados, así como que se les informará de ello en las notificaciones que reciban; y, por último, de la existencia de remedios y sanciones en caso de incumplimiento.

116 Art. 7 Circular 1/2019 AEPD recoge en detalle las garantías a cumplir. En la misma línea y con las mismas garantías se pronuncia el Documento de Orientación de la Comisión Europea sobre Elecciones libres y limpias, 2018. 
competencias pueden añadir garantías adicionales. Debemos señalar aquí que estas medidas están planteadas para los sujetos que concurran a un proceso electoral, para los que hayan presentado candidaturas, pero si dichos sujetos no resultasen proclamados, pierden toda habilitación legal para tratar las opiniones políticas de los electores, debiendo interrumpir el tratamiento y suprimir los datos tratados.

Estas garantías, como también concreta la Circular, deberán llevarse a cabo antes, durante y después del periodo electoral, ${ }^{117}$ y todas ellas serán configuradas desde los principios de privacidad desde el diseño y por defecto de los que parte igualmente el RGPD. ${ }^{118}$

Antes del comienzo del periodo electoral se deberán llevar a cabo medidas como la elaboración de un registro de actividades, una evaluación de impacto, la consulta previa a la AEPD — por lo menos 14 semanas antes del inicio del periodo electoral- ${ }^{119}$ la designación de un Delegado de protección de datos y, en su caso, si existiera encargado del tratamiento, la celebración del correspondiente contrato. En relación con las evaluaciones de impacto, dada la especialidad de la información tratada y la posibilidad que las tecnologías ofrecen de tratar los datos habiéndolos obtenidos de terceros, se debe prestar una especial atención a los mecanismos necesario para subsanar los riegos que puedan llegar a producirse, atendiendo especialmente a la legalidad del tratmaiento y a los requisitos de transparencia. ${ }^{120}$

Durante el periodo electoral, se podrá iniciar el tratamiento y, en primer lugar, habrá que cumplir con obligaciones como las de información y transparencia, más allá de cumplir con el resto de exigencias previstas en la normativa de protección de datos. Dicha información, realizada por el responsable o por el tercero del que se recojan datos, «deberá realizarse en forma concisa, transparente, inteligible y de fácil acceso, con un lenguaje claro y sencillo». ${ }^{121}$ En todo caso, en relación con las medidas de seguridad concretas a implementar, la Circular se refiere a técnicas como la pseudonimización o la anonimización, que eviten que los datos sean accesibles a un número indeterminado de personas sin intervención humana. Asimismo, se indica que estas medidas «deberán ser lo más rigurosas que permita el estado de la técnica». Asimismo, si se produjera alguna incidencia en relación con las mismas o se produjera una violación de la seguridad de los datos relativos a las opiniones políticas, deberá informarse a la AEPD y, por regla general, también a los afectados. ${ }^{122}$

117 Art. 9 Circular 1/2019 AEPD.

118 Art. 25 RGPD.

119 En relación con esta medida concreta, la Circular 1/2019 AEPD señala que no será necesario realizar la consulta si el responsable justifica que adoptará las medidas opotunas para mitigar el impacto del tratamiento que va a realizar. La justificación implicará que deberá remitirse a la AEPD el análisis de riesgos y la evaluación de impacto junto a la justificación de las medidas adoptadas, lo que deberá hacer, también, al menos 14 semanas antes del inicio del periodo electoral.

120 Documento de Orientación de la Comisión Europea sobre Elecciones libres y limpias, 2018.

121 Art. 8 Circular 1/2019 AEPD.

122 Art. 10 Circular 1/2019 AEPD, en relación con lo previsto en los arts. 33 y 34.3 RGPD, que señala que no será necesario la comunicación al interesado si el responsable ha adoptado medidas de protección 
Por último, terminado el periodo electoral o no habiendo sido proclamados, se deberá garantizar la supresión de los datos personales, o en su caso, su bloqueo. La supresión deberá realizarse conforme a determinados procedimientos que deberán quedar debidamente documentados. ${ }^{123}$

Como una garantía más rodeando el tratamiento de datos personales durante el proceso democrático, la Circular 1/2019 AEPD indica que se deberá facilitar, de un modo sencillo y gratuito, el ejercicio de todos los derechos del interesado, con especial referencia al derecho de oposición. Recordamos en este punto que la LOREG prevé este derecho en el art. 39.3 LOREG respecto de la copia del censo entregada a los candidatos para el envio de propaganda vía postal, y en el art. 58.bis). 5 en relación con las opiniones políticas utilizadas por los partidos políticos en la realización de sus actividades políticas durante el periodo electoral, y que esta posibilidad se desarrolla también con la petición al Instituto Nacional de Estadística (INE), del que depende la Oficina del Censo Electoral. ${ }^{124}$ Asimismo, en relación con los derechos de los electores, una forma de evitar el perfilado de las personas, es, como se ha defendido desde el Consejo de Europa, proteger el derecho al anonimato en Internet, regulando y limitando de forma estricta la creación y el uso de perfiles, en todo tipo de contextos. ${ }^{125}$

Más allá de estas garantías, la Circular 1/2019 de la AEPD establece un par de garantías adicionales que consideramos esenciales para respetar la privacidad de los electores y garantizar la integridad y neutralidad del proceso electoral. ${ }^{126}$ Así, en primer lugar señala el supuesto en el que los datos se obtengan de terceros que no están actuando como encargados del tratamiento — caso de los prestadores de servicios on line como Facebook o de cualquier otra red social, por ejemplo- - y se exige a los responsables «comprobar que dichos datos fueron obtenidos de manera lícita y cumpliendo con todos los requisitos del RGPD, especialmente

adecuadas, como por ejemplo, el cifrado; se hayan tomados medidas que garanticen que no volverá a producirse la incidencia; y si en lugar de informar personalmente, porque supone un esfuerzo desproporcionado, lo ha hecho mediante una comunicación pública o medida semejante.

123 El art. 9 Circular 1/2019 AEPD se refiere expresamente a dos normas: a la Norma ISO 27001:2013, titulada «Seguridad de la información» y a la Norma UNE- EN15713:2010, titulada «Destrucción del Material Confidencial. Código de Buenas Prácticas», aunque también se refeire a «cualquier otra metodología de reconocido prestigio para la destrucción de la información debidamente documentada».

124 Pero la verdad que su solicitud todavía no puede considerar un método sencillo, pues se exige estar en posesión de un certificado electrónico, lo que puede llegar a dificultar el ejercicio del derecho para muchas personas que no tengan dicha posibilidad. (Acceso disponible en: https://sede.ine.gob.es/oposicionPartidos/ presentacion). En relación con este derecho, el colectivo «Sequoya Group», a través de la «Fundación para la defensa de la privacidad y los derechos digitales» lanzó una iniciativa crowdfunding en abril de 2019 basada en la elaboración de una «Lista Viernes», que en su primera semana de funcionamiento registró más de 5.000 personas inscritas, aunque no era bien vista por los partidos políticos. Así, por ejemplo, en la Memoria del análisis de impacto normativo de la Circular 1/2019 AEPD se recogen las opiniones contrarias a la existencia de este tipo de Listas, semejantes a las conocidas como Listas Robinson (en concreto la opinión contraria de Ciudadanos y de la APEP).

125 Informe de la Comisión de Venecia sobre Tecnologías Digitales y Elecciones, 2019, Apdo. 83.

126 Art. $7.9^{\circ}$ y $10^{\circ}$ Circular $1 / 2019$ AEPD. 
que el tercero tiene una legitimación específica para obtener y tratar dichos datos y que ha informado expresamente a los afectados de la finalidad de cesión a los partidos políticos». Y, en segundo lugar, se indica que para el caso de querer llevar a cabo, con los datos de los electores, decisiones automatizadas o elaborar perfiles se deberán adoptar medidas adicionales, empezando por informar de ello a los titulares de los datos y, como mínimo, «el derecho a obtener intervención humana por parte del responsable, a expresar su punto de vista y a impugnar la decisión». ${ }^{127}$

Junto a las garantías recogidas por la Circular 1/2019, existen otros mecanismos previstos legalmente que podrían ser utilizados para completar la protección de las opiniones políticas tratadas por los partidos políticos. Nos referimos, concretamente, a los llamados códigos de conducta.

Tanto el RGPD como la LOPDGDD prevén la posibilidad de elaborar códigos de conducta, aprobados por las Autoridades competentes, en sectores concretos como puede ser el contexto electoral. ${ }^{128} \mathrm{Ha}$ sido el SEPD el que ha propuesto también la elaboración de este tipo de códigos en el terreno de la comunicación electoral con el fin de mejorar y demostrar la transparencia del sector. Según el SEPD la elaboración de un código de conducta puede inspirar a los partidos políticos, a las campañas y a otras asociaciones de carácter social y político a debatir sobre la dimensión ética del tratamiento de los datos personales en los procesos democráticos. ${ }^{129} \mathrm{Y}$ no sólo por ofrecer mayor transparencia de cara a los ciudadanos, sino por ofrecer «unas reglas de juego compartidas». ${ }^{130}$ Así, por ejemplo, en la Unión Europea, la aprobación de un Código de Buenas Prácticas en los Procesos electorales en septiembre de 2018 implicó la aprobación del Código aprobado por Google, Facebook y Twitter con motivo de las elecciones europeas celebradas en mayo de 2019. ${ }^{131}$ Se garantiza así la transparencia de la publicidad política, permitiendo a los electores conocer el motivo por el que han recibido y sido objeto de la propaganda electoral más allá de conocer el origen de la misma y la verificación de dicha identidad o de la relación entre el patrocinador y el responsable del tratamiento, así como la cuantía invertida.

127 Cumpliendo así con el art. 22 RGPD.

128 Art. 40 RGPD y art. 38 LOPDGDD.

129 Dictamen 3/2018 SEPD.

130 Martínez Martínez, R. «Partidos, algoritmos y...», op. cit., p. 135.

131 Código de buenas prácticas en materia de desinformación, de la Unión Europea, de 26 de septiembre de 2018 (Disponible on line: https://ec.europa.eu/digital-single-market/en/news/code-practice-disinformation), Pto. I (Objetivos).). Vid., en concreto, Pto. I, Objetivos; Pto. II, Compromisos, en concreto, Pto. II.B. Publicidad política y publicidad sobre aspectos concretos; y Pto. II.D. Capacitación de los consumidores. Las tres plataformas citadas se comprometieron (y cumplieron) a notificar mensualmente las medidas adoptadas de cara a las elecciones al Parlamento Europeo de mayo de 2019. Entre los informes presentados, el de Twitter señaló la aprobación entre sus normas de una nueva política de integridad de las elecciones, prohibiendo tratar categorías específicas de conducta y contenidos manipuladores, tales como información engañosa sobre la manera de participar en las elecciones e intimidación de los votantes. 
Así las cosas, la transparencia es esencial en todo proceso democrático, máxime en la comunicación política en lo que contribuye a la formación de una opinión pública, pues nada es más cierto que el hecho de que «la propaganda peligrosa en una sociedad democrática es aquella que no es reconocida como propaganda». ${ }^{132}$ Por este motivo, en nuestra opinión, se potenciaría la transparencia y se respetaría la esencia del derecho a la protección de datos —el poder de disposición- si se confirmara en nuestro ordenamiento jurídico la consideración de la propaganda electoral digital como publicidad comercial y su sometimiento a las reglas del spam previstas en la LSSI. Sería conveniente que el marketing político se sometiera a los principios y prohibiciones previstos en la normativa del comercio electrónico y, por lo tanto, a la exigencia del consentimiento de los destinatarios para poder ser enviado. ${ }^{133}$

Esto evidencia, por otro lado, que las normas de protección de datos, así como las electorales, deben colaborar no sólo entre ellas sino con las normas de privacidad electrónica y de las telecomunicaciones, más allá del sector audiovisual y la vía de propaganda electoral por los medios de comunicación tradicionales, sino sobre todo por el papel que en este terreno juegan los reguladores y operadores y la posibilidad que se tiene de evitar la manipulación de la información en línea. En el terreno de las campañas electorales, mucho más si hablamos de las seguidas en el entorno on line, existe un evidente problema a la hora de aplicar los principios de transparencia e iguadad de oportunidades. Por todo ello, la colaboración entre las Autoridades de control existentes a nivel electoral, audiovisual y de telecomunicaciones, y de protección de datos es necesaria con el fin de que entre las mismas se puedan intercambiar información sobre las prácticas de recogida y tratamiento de datos que se aplican en las campañas políticas (con o sin ayuda de terceros), lo que redundará en un mejor control y evaluación del cumplimiento de las funciones que los partidos políticos tienen constitucionalmente asignadas en el marco del cumplimiento de los requisitos del RGPD y la LOPDGDD, incluyendo la rendición de cuentas, la legalidad, la transparencia y la igualdad a la hora de tratar datos personales. ${ }^{134}$ Es la propia naturaleza sin fronteras de Internet y la participación del sector privado lo que provoca que los desafíos que se plantean en los procesos electorales sean particularmente complejos y hacen necesaria la ya mecionada colaboración para garantizar unas elecciones libres y el correcto funcionamiento de la democracia en el futuro. ${ }^{135}$

Por último, se hace necesario un sistema de sanciones efectivo ante el incumplimiento de la normativa de protección de datos si se quiere persuadir de utilizar

132 García Sanz, R.M., «Tratamiento de datos...», op. cit., p. 145; y Jason, S., How Propaganda Works, Princeton University, New Jersey, 2015, p. 46.

133 García Mahamut, R., «Partidos políticos y... », op. cit., p. 327.

134 Dictamen 3/2018 SEPD

135 Así lo manifestó el Informe de la Comisión de Venecia sobre Tecnologías Digitales y Elecciones, 2019, Apdo. 153. 
los datos personales para manipular la voluntad de los ciudadanos. ${ }^{136}$ Por esta línea apostó la Unión Europea en las últimas elecciones al Parlamento europeo de 2019, estableciendo que aquellos partidos políticos que no pudieran verificar un comportamiento adecuado respecto de la normativa de protección de datos y aprovecharan las normas de protección de datos con el fin de influir en el resultado de las elecciones, serían castigados con el fin de proteger la integridad del proceso democrático estableciendo sanciones financieras. ${ }^{137}$ Esto es así en tanto que para que los derechos fundamentales sean prácticos y efectivos, no se requieren sólo de garantías previas, sino de recursos efectivos ante su incumplimiento, ante hechos como la opacidad de la decisión electoral tomada, el desconocimiento de la decisión que les afecta o sobre el consentimiento prestado, que muestran una evidente dificultad para asignar la responsabilidad, lo que complica también la comprensión de las personas sobre a quién dirigirse para tratar su queja. ${ }^{138}$

\section{A MODO DE REFLEXIÓN FINAL}

Un correcto tratamiento de los datos personales implica un poder de control y disposición sobre los mismos por parte de sus titulares. Si ese control se pierde por un uso inadecuado de los mismos, la lesión no se produce sólo para la vida privada de sus titulares, sino que afecta al funcionamiento democrático de nuestra sociedad. Si un sujeto no sabe qué información se conoce sobre él y cómo va a ser utilizada, dejará de participar en la sociedad de la que forma parte. Pero si, además, la sospecha y confirmación sobre el uso indebido recae sobre sus futuros gobernantes, la perdida de confianza en los mismos provocará el debelitamiento de la propia esencia de la democracia. ${ }^{139}$

La bienintencionada aprobación del art. 58.bis).1 LOREG, tendente a evitar la manipulación de la opinión pública y casos como el de Cambridge Analityca, surtió una percepción contraria y distorsionada. Es cierto que la calidad y técnica legislativa puede que no fuera la más acertada, ${ }^{140}$ y que faltara concreción

136 García Mahamut, R., «Partidos políticos y... », op. cit., p. 324 y pp. 318-319, quien recuerda que son innumerables las ocasiones en las que el envío de publicidad partidaria fuera del período electoral ha sido sancionada por la AEPD y de ahí también la consideración de la JEC de que «al no tipificarse como infracción electoral el uso de los datos de censo en actos de campaña electoral, su uso indebido debe combatirse mediante denuncia ante la Agencia Española de Protección de Datos o mediante acciones judiciales» (Acuerdo de la JEC de 27 de septiembre de 1999).

137 Art. 10.bis) Reglamento (UE, Euratom) 2019/493, que recoge el Procedimiento de verificación relativo a las infracciones de las normas de protección de los datos personales (DOUE L 85, de 27 de marzo).

138 Dictamen 3/2018 SEPD.

139 Sobre esta pérdida de confianza, vid. García Mahamut, R., «Partidos políticos y... », op. cit., p. 333; y García SANZ, que mantiene el incremento de la desconfianza si no se establecen controles oportunos.

140 Para BorJa Adsuara «el recurso de inconstitucionalidad no se admite — por unanimidad- por una mala calidad técnica, sino porque hay indicios de que atenta contra los intereses y derechos fundamentales 
-motivado, todo hay que decirlo, por las circunstancias políticas del momento-; y es cierto que la AEPD — a pesar de su excelente papel en todo este entramado - no es la vía para hacer lo que le corresponde al legislador. Pero la repercusión de lo que se produjo y los efectos de la falta de regulación del tema — que no de la prohibición — pueden producir graves daños en la legitimidad de nuestro sistema democrático.

La regulación de los medios tecnológicos y la protección de los datos personales en las actividades electorales con el fin de evitar la manipulación política no es una novedad. El no regular, no evita que el ilícito se produzca. La técnica de no regular algo que en la práctica todos sabemos que se hace - ejemplo de Cambridge Analityca-, es ponernos una benda en los ojos. El uso de las nuevas tecnologías por parte de partidos políticos y de otras organizaciones, ya no sujetas a principios y deberes constitucionales, ${ }^{141}$ es algo inevitable. El problema es real y urgente, y es probable que empeore a medida que más personas y cosas se conectan a Internet y los sistemas de Inteligencia Artificial aumenten. ${ }^{142}$

La cuestión no es prohibir de forma generalizada, sino regular con garantías y controles precisos y detallados y hacer que se cumplan los controles y se sancionen los incumplimientos. La solución pasa por permitir y «abrir un escenario normativo más flexible que permita a los partidos hacer un uso de datos personales de los electores que hoy no contiene el censo electoral pero cuyo tratamiento y uso esté sujeto a reglas claras y a procedimientos sancionadores expresos». ${ }^{143}$ De esta forma, las ventajas son claras en todos los terrenos, pues los partidos políticos podrían comunicarse con los electores de forma rápida y económica, además de personalizada, y existirían normas claras y precisas sobre cómo tratar la información de los votantes y cómo dirigirse a los mismos, preservando su privacidad. ${ }^{144}$

El desafío es aprovechar la tecnología de manera que ayude a las personas a participar de una forma más libre y eficaz en la toma de decisiones políticas y en la elección de sus representantes. Si no existen normas claras y concretas, con controles y sanciones igualmente concretos, que logren un equilibrio entre los intereses de los partidos políticos y el respeto a la privacidad, se producirá una «alteración definitiva de las reglas del juego democrático». ${ }^{145}$ Se trata de plantearnos si queremos tener ciudadanos libres e informados, que opinen y participen, o sujetos cuantificables por lo que valen sus datos. ${ }^{146}$

de los ciudadanos». Vid. Adsuara Varela, B. / Martínez Martínez, R., «Debate sobre el...», op. cit.. 141 En este mismo sentido, se pronuncio el SEPD en su Dictamen 3/2018, al concluir que: «No basta con confiar en la buena voluntad de los agentes comerciales que, en última instancia, no rinden cuentas».

142 Conclusiones Dictamen 3/2018 SEPD.

143 García Mahamut, R., «Partidos políticos y... », op. cit., p. 336.

144 En este mismo sentido, como se recoge en el Documento de Orientación de la Comisión Europea sobre Elecciones libres y limpias, 2018, «solo una aplicación firme y coherente de las normas ayudará a proteger la integridad de la política democrática».

145 García Mahamut, R., «Partidos políticos y... », op. cit., p. 334.

146 Dictamen 3/2018 SEPD. 
TITLE: Political parties, political opinions and Internet: violation of the right to personal data

ABSTRACT: Electoral processes do not escape the digital transformation that our society is undergoing. The necessary adaptation of electoral regulations to the use of digital technologies implies respect for personal data protection regulations and the existence of adequate guarantees that prevent political parties from manipulating citizens' votes for the information they know or get to know about them through the Internet. The modification of article 58.bis). 1 of Organic Law 5/1985, of the General Electoral System (LOREG), allowing political parties to collect personal data related to the political opinions of citizens, provoked from beadlines, citizen criticism and interesting debates by experts in the field to the proposal by the Ombudsman of an appeal of unconstitutionality against said possibility. The Constitutional Court in the Jugdment 76/2019 ends the debate by manifesting not only the unconstitutionality of the contested precept, but also by demonstrating the importance of protecting citizens' personal data with due guarantees, especially when these data are a reflection of their political ideology and their treatment affects the correct democratic functioning of our State.

RESUMEN: Los procesos electorales no escapan a la transformación digital que vive nuestra sociedad. La necesaria adecuación de la normativa electoral al uso de las tecnologías digitales implica el respeto a la normativa de protección de datos personales y la existencia de garantías adecuadas que eviten la manipulación del voto de los ciudadanos por lo que los partidos políticos conozcan o lleguen a conocer de ellos a través de Internet. La modificación del artículo 58.bis).1 de la Ley Orgánica 5/1985, del Régimen Electoral General (LOREG), permitiendo a los partidos políticos recoger datos personales relacionados con las opiniones políticas de los ciudadanos, provocó desde titulares de prensa, críticas ciudadanas e interesantes debates de expertos en la materia hasta el planteamiento por parte del Defensor del Pueblo de un recurso de inconstitucionalidad contra dicha posibilidad. El Tribunal Constitucional, en la Sentencia 76/2019, puso fin al debate manifestando no sólo la inconstitucionalidad del precepto impugnado, sino evidenciando la importancia de proteger con las debidas garantías los datos personales de los ciudadanos, máxime cuando estos datos son un reflejo de su ideología política y su tratamiento afecta al correcto funcionamiento democrático de nuestro Estado.

KEY WORDS: electoral activity, elections, political parties, political opinions, data protection, LOREG.

Palabras Clave: actividad electoral, elecciones, opiniones políticas, partidos políticos, protección de datos, LOREG.

FECHA RECEPCIÓN: 05.07.2019

FECHA ACEPTACIÓN: 11.09.2019 